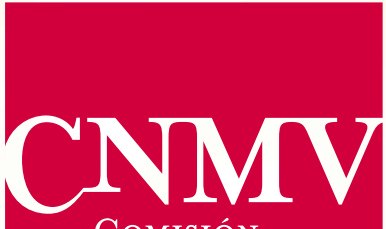

Comisión

NAGIONAL

DEL MERCADO

DE VALORES
Deconstructing systemic risk: A reverse stress testing approach

Javier Ojea-Ferreiro

Working paper

No. 74 



\title{
Deconstructing systemic risk: A reverse stress testing approach ${ }^{1}$
}

\author{
Javier Ojea-Ferreiro ${ }^{2}$
}

\begin{abstract}
The financial sector faces different systemic events. The early recognition of these events is a key step to monitor and track possible financial crises. Three main questions arise related to systemic risk, and they deal with their quantification, their probability of occurrence and the role of main contributors. This paper proposes a methodology based on a reverse stress test exercise to shed light on these questions. Time series and cross-section information regarding systemic risk are obtained. Further, we explore how these results of systemic assessment could change depending on key parameters in a Gaussian framework and, finally, a small empirical exercise is performed.
\end{abstract}

\section{Working paper}

No. 74

December 2020

1 Any comment or suggestion is very welcome. The views expressed are those of the individual author and do not necessarily reflect those of the CNMV. All errors are my own. I thank Eudald Canadell for the support in the production of this work. Also, I would like to show my gratitude to José Alberto Toribio and Miryam Santos, who have provided invaluable help in the construction of the database. A preliminary version of this article was presented at Mathematical and Statistical Methods for Actuarial Sciences and Finance Conference 2020 (eMAF2020). I really appreciate the useful comments provided by the participants at this conference.

2 Complutense Institute of Economic Analysis (ICAE) and Joint Research Centre of the European Commission (JRC). Via E. Fermi, 2749, 21027 Ispra, Italy. Emails: jojea@ucm.es/Javier.Ojea-Ferreiro@ec.europa.eu. All errors are my own. The views expressed are those of the author and do not necessarily reflect those of the JRC.

This article has been entirely produced during a research period at the CNMV 
The CNMV publishes this Working Paper Series to spread research in order to contribute towards greater knowledge of the stock markets and their regulation.

The opinions in this Working Paper are the sole responsibility of the author and they do not necessarily coincide with those of the CNMV.

The CNMV distributes its reports and publications via the Internet at www.cnmv.es

(C) CNMV. The contents of this publication may be reproduced, subject to attribution.

ISSN (digital edition): 1988-2025

Layout: Cálamo y Cran 


\section{Table of contents}

$3 \quad$ Tools and measures for systemic risk using the market-based approach 11

3.1 Marginal Expected Shortfall 11

3.2 Component Expected Shortfall 12

$\begin{array}{lll}3.3 \Delta C O E S & 12\end{array}$

3.4 New framework for assessing systemic risk coming from the relationship between systemic risk measures 13

$4 \quad$ A toy financial model $\quad 17$

$5 \quad$ An empirical application to Spanish funds data 23

5.1 Data 23

5.2 Methodology 27

$\begin{array}{lll}5.3 & \text { Results } & 28\end{array}$

6 Conclusions $\quad 33$

\begin{tabular}{ll} 
References & 35 \\
\hline
\end{tabular}

\begin{tabular}{lr} 
Appendices & 39 \\
\hline
\end{tabular} 



\section{Introduction}

The 2008 great financial crisis, the European sovereign debt crisis and the COVID-19 crisis have brought about new challenges for the European Central Bank (ECB) policy concerning macroprudential supervision. The macroprudential oversight should prevent the financial sector from bringing about a breakdown of the economic system (ECB, (2010a). According to the ECB (2010b), systemic risk can be defined as the risk of experiencing systemic events, which are financial failures likely to translate into adverse effects on welfare in the economy. There are plenty of features of the financial system that make financial sectors susceptible to these systemic risk sources, e.g. externalities through transmission channels, asymmetric information due to agency problems and powerful feedback and amplification mechanisms such as fire sales and herd behaviour.

In this article a methodology to build a systemic risk indicator is proposed that looks into tail events to compute their quantitative impact, their probability of occurrence and a set of institutions that could explain the overall losses when the distress event materialises. This approach takes into account the individual features of each institution and its systemic relevance to assess the quantitative impact of a systemic event. The tail dependence between the financial firms in the system provides the probability of occurrence. The difference between the marginal contribution of financial firms to the aggregate losses in the system and their tail behaviour that could lead to those aggregate losses in an adverse scenario indicates the relative risk of each firm over the whole financial system. The properties of the proposed model are studied using a Gaussian model. Although the normality assumption is not fulfilled in the real world, these results can be interpreted in terms of conditional normality, where a structural change in the parameters of the Gaussian model might explain the kurtosis presented in financial returns (Leon Li and Lin, 2004). The Gaussian model shows that the sign of this difference between the marginal contribution and their tail behaviour is related to the relative volatility of the firm returns. Also, the Gaussian model shows that the higher the correlation between institutions is, the closer this difference is to zero, becoming a systemic risk reflected in an increase of the overall losses and their probability. Weighting this difference by its systemic importance provides a ranking criterion where the institutions at the top are those which present a higher relative risk and characteristics that make them potentially systemic. Systemic relevance might have been computed in different ways, depending on the sector within the financial system, as they are exposed to different systemic events, e.g. market capitalisation and leverage ratio for banks, or liquidity ratios and assets under management for investment funds. This study also performs a small empirical exercise to compare different systemic risk measures in the context of investment funds for a sample of 99 Spanish investment funds for the period 2009-2020. 
This article contributes to several branches of the literature. First, it continues the study of comparison between measures of systemic risk, following Benoit et al. (2013), Kleinow et al. (2017) and Guntay and Kupiec (2014). There is a gap in this literature regarding the role of the proxy for the financial market employed to build systemic risk measures. This study looks, both in a Gaussian model and also in the empirical exercise, at the implications of the construction criterion of the financial system for the assessment of systemic risk. The standard deviation and the weight of the firms to build the proxy for the financial market could be as important as the correlation between firms.

Second, the proposed methodology is innovative in its implementation process, following the idea of a reverse stress test. Assuming that all the firms in the financial system are experiencing losses in an overall adverse scenario, i.e. the diversification benefits fade out, the aggregate losses are obtained as the sum of the weighted losses of the firms. Then, the probability of occurrence of these aggregate losses can be quantified, transforming the multivariate probability framework of mutual dependence across financial firms into a single probability space for the financial market. Finally, following the same core idea of a reverse stress test, the expected behaviour of each institution that could lead to this level of aggregate losses is obtained. A ranking is built comparing the expected performance of each institution to its tail behaviour and weighting this difference by its relative importance.

The remainder of this paper is structured as follows. Section 2 introduces the literature about systemic risk from an Expected Shortfall approach. Section 3 presents goals, formulas and interpretations of the different systemic risk measures. Section 4 presents a toy financial model to study how rankings, probabilities and overall losses can change depending on the parameter inputs under a Gaussian framework. Section 5 conducts an empirical exercise using real data from Spanish investment funds. Finally, section 6 concludes the article. 


\section{Literature review}

Trichet (2009) points out the need of high-frequency systemic risk measures due to the speed of the crisis spillovers. Several high-frequency measures have been proposed based mainly on market data. Some market data based measures are the Marginal Expected Shortfall (MES) by Acharya et al. (2012), the Component Expected Shortfall (CES) by Banulescu and Dumitrescu (2015), the Delta Conditional Value-at-Risk ( $\triangle \mathrm{CoVaR}$ ) by Adrian and Brunnermeier (2016), and the Systemic RISK (SRISK) by Brownlees and Engle (2016). Each measure tries to put forward a certain feature of the systemic event.

For instance $M E S$ is the conditional return of the financial firm when the market as a whole is in distress, whereas CES is the absolute contribution of each firm to the financial market crisis. Although from a time-series perspective MES and CES are almost identical, in the cross-sectional series there is a significant difference due to the inclusion of a size factor in the CES. Benoit et al. (2013) and Benoit et al. (2017) point out similarities between MES ranking and ranking based on market $\beta$ under Gaussian assumptions. Due to that, Guntay and Kupiec (2014) conclude that MES is a measure where systemic and systematic risk are mixed, given an unreliable and noisy view of systemic risk. Löffler and Raupach (2017) and Kleinow et al. (2017) support the same idea. This is why these authors advocate combining several systemic risk measures to identify systemically important financial institution (SIFIS).

The Delta Conditional Value-at-Risk $(\triangle \mathrm{CoVaR})$ measures the change in the value-atrisk of the financial market when the firm moves from normal to distress times. The original definition proposed by Adrian and Brunnermeier (2016) suffered from several drawbacks among which the most important were the impossibility to perform backtesting on Conditional Value-at-Risk $(\mathrm{CoVaR})$ and the counterintuitive fact that CoVaR is not a monotonically increasing function of the dependence between the firms and the financial system (Mainik and Schaanning, 2014; Zhang, 2015; Bernard et al., 2013). Girardi and Ergün (2013) propose a modification of CoVaR definition that deals with these issues. However, most of the articles concerning comparison between systemic risk measures as Benoit et al. (2017), Guntay and Kupiec (2014) or Löffler and Raupach (2017) use the original definition in spite of its problems. Moreover, CoVaR has some limitation given its nature, i.e. it does not satisfy the subadditive property (see Artzner et al., 1999; Acerbi and Tasche, 2002). This issue is solved when the value-at-risk dimension changes to an expected shortfall framework, i.e. building systemic risk measures based on Conditional Expected Shortfall (CoES). Delta Conditional Expected Shortfall ( $\triangle C O E S)$ still cannot be aggregated, unlike $C E S$ or SRISK.

Finally, SRISK tries to assess the amount of capital needed by a firm in distress when the market is also in distress. For this purpose, Brownlees and Engle (2016) 
combine market and accountant data taking into account the common exposure of the firms to the financial market, the size and the leverage of institutions. The fact of using accountant data may introduce a discrepancy problem because of the differences between accounting systems. Moreover, the accountant data is scarce and only available at a low frequency. The sub-prime crisis has shown us that financial imbalances may come from off-balance sheet activities, adding an additional challenge to SRISK. Scott et al. (2016) claim that SRISK can be appropriate for measuring systemic risk in the banking sector where the accountant data and the market leverage ratio may convey information about different business lines, but not for assessing systemic risk in other financial groups as the insurance sector. Salleo et al. (2016) find SRISK highly correlated with the leverage ratio, having doubts about the use of SRISK as a benchmark for supervisory stress tests.

Constâncio (2017) raises attention to the two main systemic risks stemming from the non-bank financial sector that have not been captured properly by stress tests and analytical tools for systemic risk, which have been built bearing the banking sector in mind.

Firstly, the increasing size and growth of the non-bank financial sector which can potentially amplify financial stability risks is to be noted. The Too-Big-To-Fail (TBTF) problem has played an important role during the 2008 financial crisis (Bernanke, 2010), and the size has increased during the last two decades (Laeven et al., 2014). Rose and Wieladek (2012) have found that the bank size has been a key determinant for public bank interventions in the United Kingdom. Size is important because there are evidences that large institutions tend to engage more in risky business lines and be funded more with short- term debt, making them vulnerable to liquidity constrains in case of crisis (Shleifer and Vishny, 2009; Boot and Ratnovski, 2012). Large banks also usually incur in moral hazard behaviour, taking excessive risk and having lower capital ratios due to the expectation of bailout (Farhi and Tirole, 2012).

Secondly, the procyclical nature of margin and haircut-setting practices may lead to the amplification of liquidity and market risk via fire sales in a distress scenario. Bernanke (2009) highlights the relevance of the Too-Connected-To-Fail (TCTF) problem to trigger out financial instabilities. International Monetary Fund et al. (2010) indicate that interconnectedness is, jointly with the size factor, an essential determinant to identify SIFIs. 


\section{Tools and measures for systemic risk using the market-based approach}

The measures employed in the literature focus on the assessment of systemic risk and the identification of the SIFIs. This section provides the specific information that each measure tries to capture and its statistical definition. The set of systemic risk measures and their relationship are studied to provide a comprehensive framework coming from the Expected Shortfall of the financial system.

Let us define the financial system return as

$$
r_{m, t}=\sum_{i=1}^{N} r_{i, t} \omega_{i, t-1},
$$

where $r_{i, t}$ stands for financial firm $i$ 's variable of interest, e.g. returns, $N$ represents the number of financial institutions and $\omega_{i, t-1}$ indicates the proxy of relative importance of firm $i$ at $t-1$, e.g. share market capitalisation over the total market capitalisation. The mean loss in a distress scenario for the financial system is a good indicator of the materialisation of the hidden pitfalls in a crisis period. The Expected Shortfall of the financial system is

$$
E S_{m, t-1}(\alpha)=-E_{t-1}\left[r_{m, t} \mid r_{m, t}<\operatorname{VaR} R_{m}(\alpha)\right]
$$

\subsection{Marginal Expected Shortfall}

The Marginal Expected Shortfall (MES) measure provides information about the mean losses of financial firm $i$ when a financial crisis occurs. This measure provides useful information concerning the average behaviour of financial institutions on a certain scenario and their conditional performance features.

MES measures the marginal contribution of an institution $i$ to systemic risk

$$
M E S_{i, t}(\alpha)=\frac{\partial E S_{m, t}(\alpha)}{\partial w_{i, t-1}}=-E_{t-1}\left[r_{i, t} \mid r_{m, t}<\operatorname{VaR} R_{m, t}(\alpha)\right]
$$

Equation (3) can be rewritten as

$$
\operatorname{MES}_{i, t}(\alpha)=-\int_{-\infty}^{\infty} r_{i, t} f_{i, t}\left(r_{i}, t \mid r_{m, t}<\operatorname{VaR} R_{m, t}(\alpha)\right) d r_{i, t},
$$

where $f_{i, t}\left(r_{i, t} t r_{m, t}<\operatorname{Va} R_{m, t}(\alpha)\right)$ is the probability density function for firm $i$ conditioned to a scenario where the financial market is below its $\alpha 100$-th quantile. 


\subsection{Component Expected Shortfall}

The CES measure indicates the contribution of each firm to the system mean losses in distress, i.e.

$$
C E S_{i, t}(\alpha)=\omega_{i} M E S_{i, t}(\alpha)
$$

There is a relationship between CES and the ES of the financial system given Equation (3)

$$
E S_{m, t}(\alpha)=\sum_{i=1}^{N} \overbrace{\omega_{i, t-1} \underbrace{E_{t-1}\left(-r_{i, t} \mid r_{m, t}<\operatorname{VER}(\alpha)\right)}_{M E S_{i, t}}}^{C E S_{i, t}} .
$$

Equation (6) points out two important advantages of CES over MES. First, CES introduces a size factor in the MES formula dealing with the TBTF problem. Second, Equation (6) shows that the $E S$ of the financial system can be expressed as a sum of $C E S$. This means that CES can be aggregated, giving information about which would be the joint contribution of a subset of institutions to the system losses in a financial crisis.

However, CES does not show the dependence with the market scenario nor give enough importance to tail features that could lead to a systemic event.

\section{$3.3 \quad \triangle C O E S$}

$\triangle C o E S_{m i}$ measure indicates the change in the Expected Shortfall of the financial system when the financial firm $i$ moves from normal times to a distress scenario, i.e.

$$
\Delta C o E S_{m \mid i, t}(\beta)=\operatorname{CoE} S_{m \mid i, t}\left(\alpha_{s}, \beta\right)-\operatorname{CoE} S_{m \mid i, t}\left(\alpha_{n}, \beta\right)
$$

where $C o E S_{m l i}$ shows the ES of the market conditioned to a specific scenario for financial firm $i$. The CoES is the coherent extension of CoVaR, i.e.

$$
\operatorname{CoES}_{m \mid i, t}(\alpha, \beta)=\frac{1}{\beta} \int_{0}^{\beta} \operatorname{CoV} a R_{m \mid i, t}(\alpha, q) d q
$$

The $\operatorname{CoVaR}_{m i}(\alpha, \beta)$, following the definition of Girardi and Ergün (2013), expresses the minimum return in the financial system with a confidence level $(1-\beta) 100 \%$ given that financial firm $i$ is below its $\alpha$ 100-th quantile, i.e.,

$$
P_{t-1}\left[r_{m, t} \leq-\operatorname{CoV} a R_{m \mid i, t}(\alpha, \beta) \mid r_{i, t} \leq \operatorname{VaR} R_{i, t}(\alpha)\right]=\beta
$$

The Expected Shortfall of the financial market is measured at two different scenarios for the firm $i$ in Equation (7). Firm $i$ faces a distress scenario where its returns are below its $\alpha$-th quantile in the numerator of Equation (7), whereas in the denominator 
the returns of firm $i$ are around its median. ${ }^{1}$ Losses not considered in normal scenarios can trigger a systemic event because of the lack of liquidity, i.e. in a normal scenario capital needs can be fulfilled without spillover effects between sectors, but in a distress scenario capital needs could lead to bankruptcy and bailout processes, leading to a contagion event from the firm $i$ to the financial market. Therefore, CoES is an unsatisfactory measure to assess the contagion because it lacks a benchmark to measure the change in the measurement of risk when a crisis occurs. Indeed, CoES and CoVaR may be enough to capture the losses in a given scenario but not the loss changes when the conditioning scenario moves. That is why Adrian and Brunnermeier (2016) conceived $\triangle C o E S$ as a difference of two CoES where the degree of distress was different.

\subsection{New framework for assessing systemic risk coming from the relationship between systemic risk measures}

Most systemic risk measures, such as MES or SRISK, define systemic risk as the assessment of losses for financial institution $i$ given a stress scenario for the financial system, with the exception of $\triangle C o E S_{m i}$ which defines the systemic risk on the opposite way. The measure obtained by exchanging conditioned and conditioning variables in Equation (7) is a risk management tool similar to the stress test, useful for tracking financial firms performance in terms of systemic risk. Whereas $\triangle C o E S_{m i}$ measures which financial institution contributes more to a financial crisis, $\triangle C o E S_{i m}$ measures which financial institution is more exposed to a contagion from the financial sector.

The MES can be expressed as the weighted sum of two sections, where one component $\left(C o E S_{i m}\right)$ is focused on the tail behaviour of firm $i$, where sunken losses arise. Figure 1 shows the MES as the area on the left of $V a R_{m, t}(\alpha)$, which is split in two sections weighted by their probability of occurrence given the distress scenario for the financial market. The threshold that divides MES in two areas is the Conditional Value-at-Risk $\left(\mathrm{CoVaR}_{i m}\right)$. Losses higher than $-\mathrm{CoVaR}$ im would occur $\beta 100$ out of a hundred times whereas losses would be lower $(1-\beta) 100$ out of a hundred times.

1 There is no consensus about the definition of tranquil times for the conditioning event. The definition employed in this article follows Ferreiro (2018). Chen and Khashanah (2014) employ the unconditional ES measure and Girardi and Ergün (2013) use a standard deviation range around the mean value of the conditioning variable. However, the former definition does not capture the relevance of a change in the conditioning variable from a normal period to a distress scenario for the conditioned variable. On the other hand, the latter definition for a tranquil scenario is not fully defined for non-Gaussian marginal distributions due to the need to use higher moments, e.g. skewness and kurtosis. 


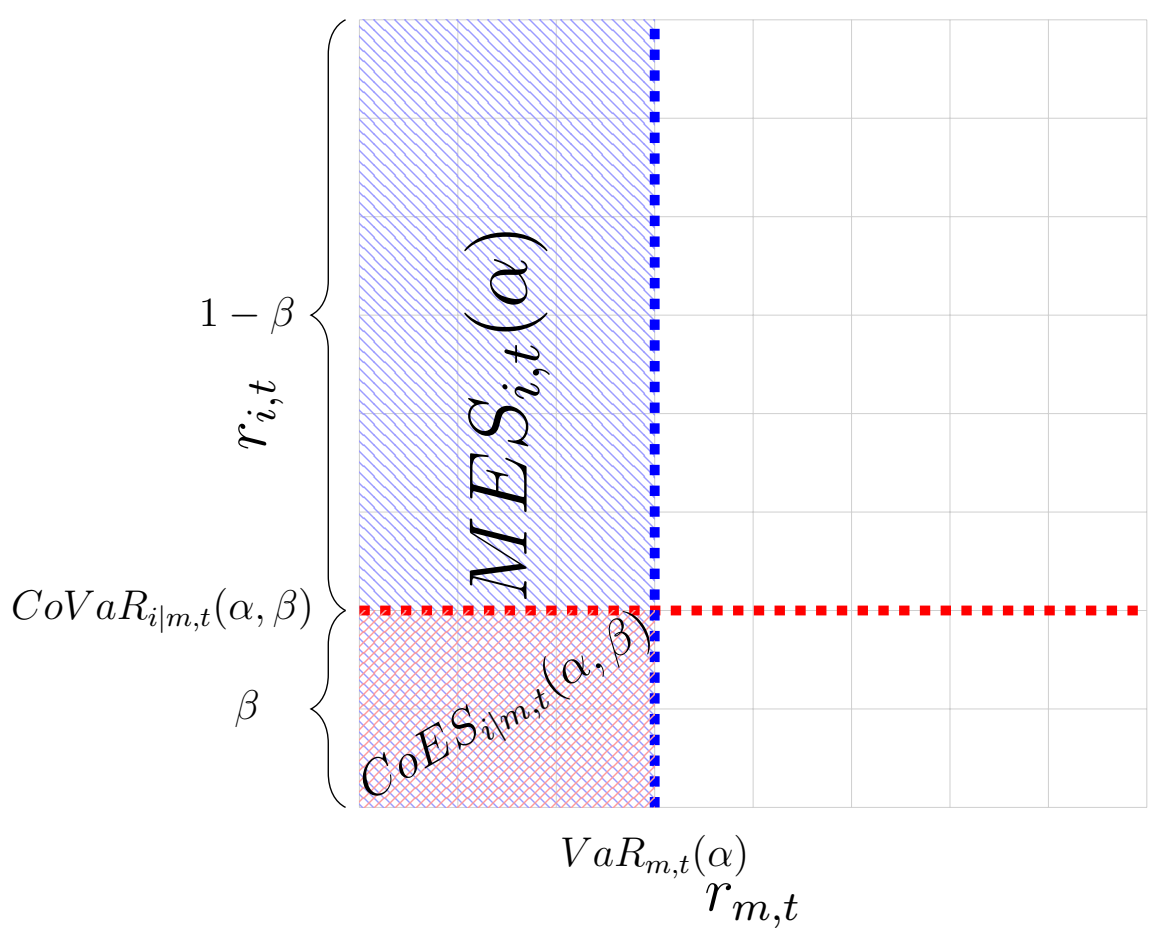

The striped blue rectangle shows $\operatorname{MES}_{i, t}(\alpha)$, while the striped red rectangle shows $\operatorname{CoES}_{i \mid m, t}(\alpha, \beta)$. Note that all the measures for institution $i$ are built on the left of the threshold $\operatorname{VaR}_{m, t}(\alpha)$ of the financial market. The Marginal Expected Shortfall can be divided into two means weighted by their probability. The threshold that divides both areas is the $\operatorname{CoVaR}_{i \mid m, t}(\alpha, \beta)$ and the area weighted by a probability $\beta$ would be the $\operatorname{CoES}_{i \mid m, t}(\alpha, \beta)$.

Expressing $M E S$ as a function of $\operatorname{CoES}_{i m}$

$$
\begin{aligned}
\operatorname{MES} S_{i, t}(\alpha)= & E_{t-1}\left(-r_{i, t} \mid r_{i, t}>\operatorname{CoVa} R_{i \mid m, t}(\alpha, \beta)\right) \\
& \underbrace{P_{t-1}\left[r_{i, t}>\operatorname{CoVa} R_{i \mid m, t}(\alpha, \beta) \mid r_{m, t} \leq \operatorname{VaR} R_{m, t}(\alpha)\right]}_{1-\beta}+ \\
& \underbrace{E_{t-1}\left(-r_{i, t} \mid r_{i, t} \leq \operatorname{CoV} a R_{i \mid m, t}(\alpha, \beta)\right)}_{\operatorname{CoES}_{i \mid m, t}(\alpha, \beta)}
\end{aligned}
$$

The interesting section of $M E S_{i, t}$ is the one in which institution $i$ is in distress, i.e. $C o E S_{i m, t}(\alpha, \beta) \beta$. In fact, the ranking according to $M E S_{i, t}$ could be quite different from the ranking following $C o E S_{i m}$ if there are hidden losses on the tail of distribution which can be overlooked when completed distribution is considered.

The link between $C o E S_{i m}$ and the $E S$ of the financial system comes from Equations (6) and (9). Moving from a marginal dimension, i.e. $M E S_{i}$, to a conditional marginal framework, i.e. $C o E S_{i m}$, implies a focus not only on the mean response of firm $i$ under an extreme scenario for the financial system but on its tail response to this scenario. 
Equation (6) can be rewritten in terms of Conditional Expected Shortfall as

$$
\begin{aligned}
E S_{m, t-1}(\alpha)= & \sum_{i=1}^{N} \overbrace{\omega_{i, t-1} \operatorname{CoE} S_{i \mid m, t}(\alpha, \beta)}^{\text {Component }} \beta+ \\
& \sum_{i=1}^{N} \omega_{i, t-1} E_{t-1}\left(-r_{i, t} \mid r_{i, t}>\operatorname{CoVS}\right.
\end{aligned}
$$

where the Component CoES is a decomposition of the Component Expected Shortfall (CES) (see Banulescu and Dumitrescu, 2015) where the focus is set on the conditional tail losses instead of the conditional mean losses.

The sum of the Component CoES would be equal to the Expected Shortfall of the financial system at a certain significance level. Under the assumption of conditional perfect dependence between institutions, i.e. firms present perfect positive correlation when the distress scenario for financial market materialises, the significance level would be $\alpha \beta$. Nevertheless, this assumption is far away from reality, so the sum of the Component CoES would be equal to the Expected Shortfall of the financial system conditioned to the fact that it is below its $\lambda$ quantile, which is unknown and can change over time. We can think of this $\Lambda$-Expected Shortfall as an extension of $\Lambda$-VaR introduced by Frittelli et al. (2014), where the quantile of the $V a R$ is not fixed, but depends on a function $\Lambda$. The properties of $\Lambda$-VaR have been studied by Burzoni et al. (2017) and its application for regulatory capital have been analysed by Hitaj et al. (2018). Hitaj et al. (2018) point that $\Lambda$-VaR captures tail risk and reacts to market swings more quickly than the $V a R$ and Expected Shortfall. A similar conclusion should be obtained from the $\Lambda$-Expected Shortfall, where the quantile $\lambda$ would be closer to $\alpha \beta$, the closer to one it is the correlation between firms when the distress scenario for the financial market materialises.

In mathematical terms

$$
E S_{m, t}(\lambda)=\sum_{i=1}^{N} \omega_{i, t-1} \operatorname{CoE} S_{i \mid m, t}(\alpha, \beta)
$$

where $\lambda=\alpha \beta$ in case of conditional perfect dependence. The quantile $\lambda$ and its distance from $\alpha \beta$ would be an indicator of the tail dependence coming from distress scenarios. The ratio $\frac{\lambda}{\alpha \beta}$ expresses how many times those losses are more probable compared to the benchmark scenario for conditional perfect dependence. $E S_{m, t}(\lambda)$ quantifies the distress event in terms of mean losses in the financial system. It is worth noticing that in this framework we obtain first the losses coming from the marginal tail behaviour in an adverse scenario, and then the probability of observing the overall mean losses is computed. Finally, following the framework of a reverse stress test, Equation (6) is used to get the contribution of each financial firm to the overall losses. The difference between the Component Expected Shortfall and the Component Conditional Expected Shortfall indicates which institution contributes more to systemic risk than it might be expected given its tail marginal behaviour in a crisis period. Hence, an institution that moves in an opposite direction 
than the remainder firms of the financial system in a systemic scenario would present higher conditional tail losses than its marginal contribution to the aggregate losses, i.e. the firm would act as a shock absorber. The consequent ranking of firms does not depend on the overall level of losses in the financial system and it might be employed to identify those institutions which are more systemic, i.e.

$$
\begin{gathered}
\sum_{i=1}^{N} \omega_{i, t-1} M E S_{i \mid m, t}(\lambda)=\sum_{i=1}^{N} \omega_{i, t-1} \operatorname{CoE} S_{i \mid m, t}(\alpha, \beta) \Longrightarrow \\
\sum_{i=1}^{N} \omega_{i, t-1}\left(M E S_{i \mid m, t}(\lambda)-C o E S_{i \mid m, t}(\alpha, \beta)\right)=0,
\end{gathered}
$$

Summing up, the proposed methodology provides three main outputs. First, the aggregate losses under a distress event $(E S(\lambda))$. Second, the probability of observing these system-wide mean losses $\left(\lambda_{100} \%\right)$. Third, the ranking that identifies those institutions that contribute more to the distress event that it would be expected under a conditional perfect dependence framework $\left(\omega_{i, t-1}\left(M E S_{i m, t}(\lambda)-\operatorname{CoES}_{i m, t}(\alpha, \beta)\right)\right.$. While the two first outputs provide time series information, the latter output gives awareness about the cross-section importance of the firms within the sample. The three outputs should be considered jointly to have a comprehensive view of systemic risk. 


\section{A toy financial model}

We employ a toy financial system model to study the properties of the proposed methodology to quantify a systemic risk event, to compute its probability and to build a ranking of the firms. This exercise would be helpful to get an idea about the information provided by this approach depending on the value of key variables. The subscript $t$ is ignored in the following explanation for the sake of simplicity. A Gaussian framework allows us to compute systemic risk measures using closed formulas. The universe of financial institutions is limited to two to build a tractable model. Proofs of those formulas are provided in Appendix A.

The returns of the financial firms are represented by

$$
\left(\begin{array}{l}
r_{1} \\
r_{2}
\end{array}\right)=\underbrace{\left(\begin{array}{l}
\mu_{1} \\
\mu_{2}
\end{array}\right)}_{\mu}+\underbrace{\left(\begin{array}{cc}
\sigma_{1} & 0 \\
0 & \sigma_{2}
\end{array}\right)}_{D^{1 / 2}} \underbrace{\left(\begin{array}{cc}
1 & 0 \\
\rho & \sqrt{1-\rho^{2}}
\end{array}\right)}_{L_{t}}\left(\begin{array}{l}
\epsilon_{1} \\
\epsilon_{2}
\end{array}\right),
$$

where $\epsilon_{1}$ and $\epsilon_{2}$ are two independent normal random variables. The returns of the financial system are given by

$$
r_{m}=\left(\begin{array}{ll}
r_{1} & r_{2}
\end{array}\right)\left(\begin{array}{c}
\omega_{1} \\
1-\omega_{1}
\end{array}\right)
$$

The Marginal Expected Shortfall is provided by

$$
M E S_{i \mid m}(\alpha)=\frac{\sigma_{i} \rho_{i, m} \phi\left(\Phi^{-1}(\alpha)\right)}{\alpha}-\mu_{i}
$$

the Conditional Expected Shortfall is

$$
\operatorname{CoES}_{i \mid m}(\alpha, \beta)=\sigma_{i}\left(\sqrt{1-\rho_{i, m}^{2}} \frac{\phi\left(\Phi^{-1}(\beta)\right)}{\beta}+\rho_{i, m} \frac{\phi(\Phi(\alpha))}{\alpha}\right)-\mu_{i}
$$

and $\rho_{i, m}=\frac{\sigma_{i} m}{\sigma_{i} \sigma_{m}}$. The standard deviation for the financial system is obtained from

$$
\sigma_{m}=\sqrt{\sigma_{1}^{2} \omega_{1}^{2}+\sigma_{2}^{2}\left(1-\omega_{1}\right)^{2}+2 \sigma_{1} \sigma_{2} \rho \omega_{1}\left(1-\omega_{1}\right)}
$$


and the covariance between the returns of the financial system and firm $i$ would be

$$
\begin{aligned}
\sigma_{1 m} & =\omega_{1} \sigma_{1}^{2}+\sigma_{1} \sigma_{2} \rho\left(1-\omega_{1}\right) \\
\sigma_{2 m} & =\left(1-\omega_{1}\right) \sigma_{2}^{2}+\sigma_{1} \sigma_{2} \rho \omega_{1} .
\end{aligned}
$$

We assume that the returns of the financial market are obtained as the sum of the returns of two financial firms that have the same size, i.e., $\omega_{1}=0.5$. Both firms are normally distributed with zero mean and standard deviation $\sigma_{1}=0.04$ and $\sigma_{2}$ is defined as $\mathrm{X}$ times the standard deviation of firm 1, i.e., $\sigma_{2}=0.04 X$, where we study values between 0.5 and 3 . The dependence between both firms can be defined by a Gaussian copula with parameter $\rho$. We set the parameters of $\alpha$ and $\beta$ equal to 0.1 so that the joint probability of the distress scenario (under conditional perfect dependence) would be equal to $\alpha \beta=0.01$.

Figure 2.a shows the probability ratio between the probability of occurrence of the mean aggregate losses provided by the model and the one that we could expect from the benchmark of conditional perfect dependence. The probability of the distress scenario could be up to almost 5 times the probability of the distress event under conditional perfect dependence. The highest increases of the probability of the distress scenario are found when the correlation parameter between firm 1 and firm 2, $\rho$, is close to one. The probability of the distress event also increases with the higher volatility of the firms within the financial system.

Figure 2.b shows different probability ratios between the actual and the probability under conditional perfect dependence. Each line indicates respectively o.5, 1, 2, 3, 4 and 5 times the probability under conditional perfect dependence. Interestingly, the red dashed line indicates that the independence between financial firms $(\rho=0)$ does not imply that the probability ratio is equal to o.1. ${ }^{2}$ This is due to the fact that the return distribution in the financial system is the result of the convolution of the weighted returns of the individual firms. Hence, there are two ways in which an individual firm would be dependent on the financial system. First, because of the dependence across the remainder financial firms; second, because the individual firm is part of the financial system although it could be independent from the remainder institutions.

Figure 2.c shows the same probability ratios as Figure 2.b, but in terms of the correlation of the returns of each financial firm with the financial system. The red line indicates the bisector where the returns of both firms present the same correlation to the financial system. It is worth noting that there is no need to have a negative correlation to the financial system to get a probability ratio below one.

2 This would be the case of conditional independence, where $\lambda=\alpha \beta^{2}$, so $\lambda /(\alpha \beta)=\beta=0.1$. 


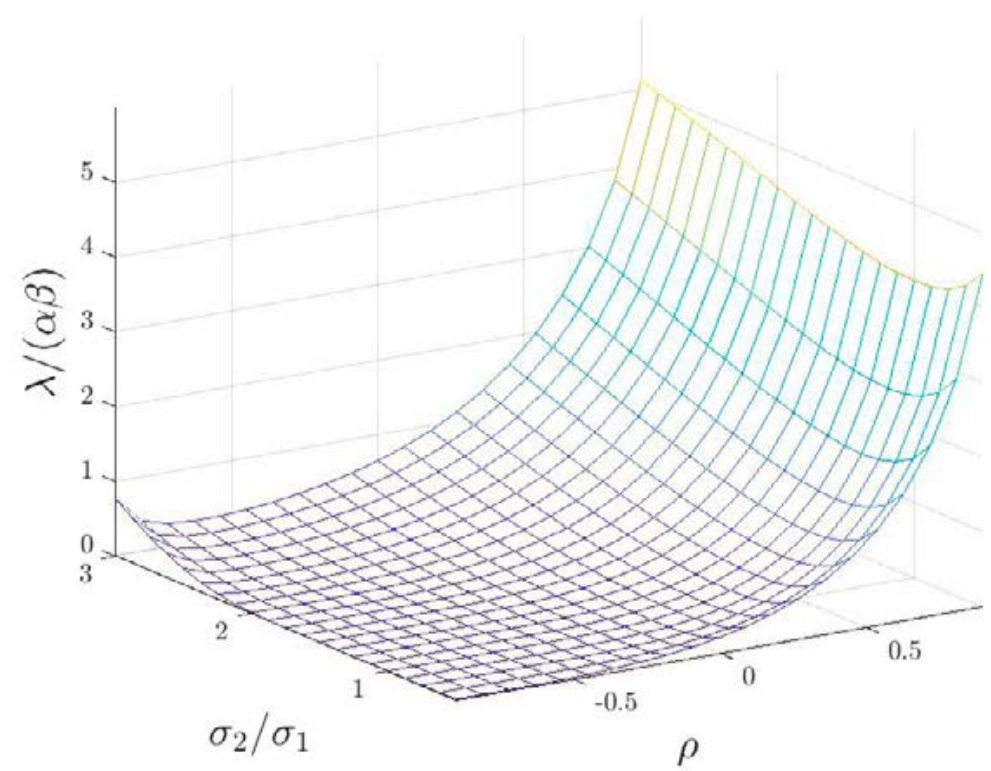

(a) Probability ratio between the probability of occurrence of the losses of the financial system ( $($ ) and the probability of the scenario under the assumption of conditional perfect dependence $(\alpha \beta)$.

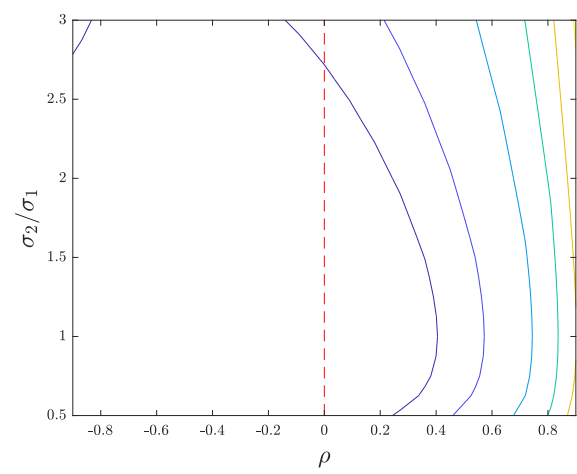

(b) Probability ratio at different levels depending on $\sigma_{2} / \sigma_{1}$ and $\rho$.

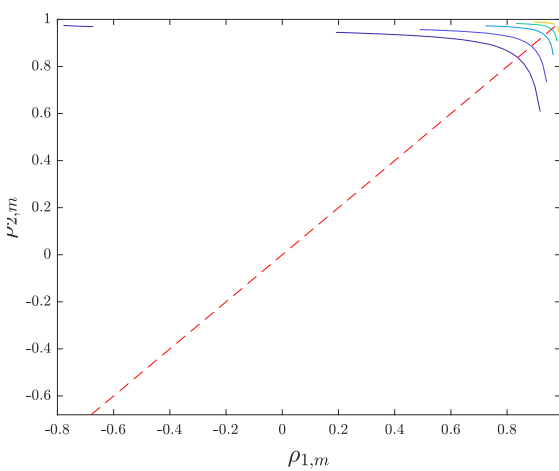

(c) Probability ratio at different levels depending on $\rho_{1, m}$ and $\rho_{2, m}$.

The probability ratio is shown (Figure 2.a, Figure 2.b) as a function of the ratio of standard deviations and the correlation between firms' returns or (Figure 2.c) as a function of the correlation between returns of each financial firm with the financial system.

The returns of the financial system is the equally-weighted sum of the returns of the individual firms. Each line (Figure 2.b, Figure 2.c) indicates respectively $0.5,1,2,3,4$ or 5 times the probability under conditional perfect dependence. The red dashed line (Figure 2.b) indicates the independence between the two financial firms or (Figure 2.c) the bisector showing equal correlation to the financial system.

The relationship between the correlation of the returns of firm 1 with the financial system and the correlation between the returns of the financial firms and its ratio of standard deviations deserve some comments. Figure 3.a shows a complex relationship between the correlation of the returns of firm 1 with the financial system, the relative standard deviation and the correlation with firm 2. Note that the higher the correlation is between firms, the higher would be the lower bound of the correlation between the returns of firm 1 and the financial system (Figure 3.b). Also, the higher the variance of the returns of firm 1 is over the variance of firm 2, the closer to one the lower bound of the correlation between the returns of firm 1 with the financial system would be (Figure 3.c). Interesting conclusions can be obtained when we focus on the combinations 
of negative correlation between assets and high variance of firm 1. Figure 3.b shows that the correlation between the returns of firm 1 and the financial system could be close to one, although the relationship of the returns of firm 1 to the remainder financial institution (firm 2) is $-90 \%$. This groundbreaking finding can be understood if we recall that the returns of the financial system are the weighted sum of the individual firms. Consequently, conditioned to an equally weighted composition of the financial system, the firm with a higher variance would be the one that more probably is driving the movements in the financial system. Also, following the same reasoning, the higher the relative size of firm 1 over firm 2 is in Equation 1, the higher the correlation between firm 1 and the financial system would be, regardless of the correlation with financial firm 2.

\section{The correlation between firm 1 and the financial system depending on key parameters}

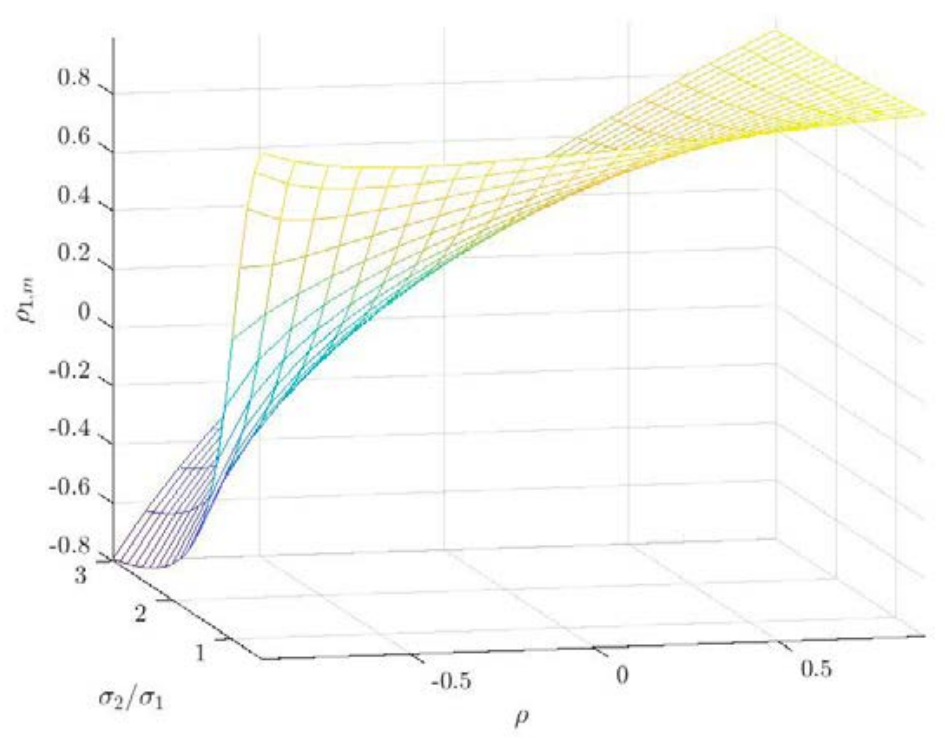

(a) $\rho_{1, m}$ depending on $\sigma_{2} / \sigma_{1}$ and $\rho$.

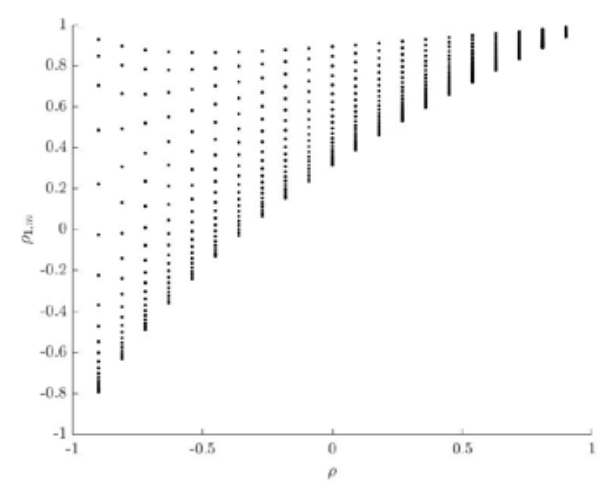

(b) $\rho_{1, m}$ depending on $\rho$.

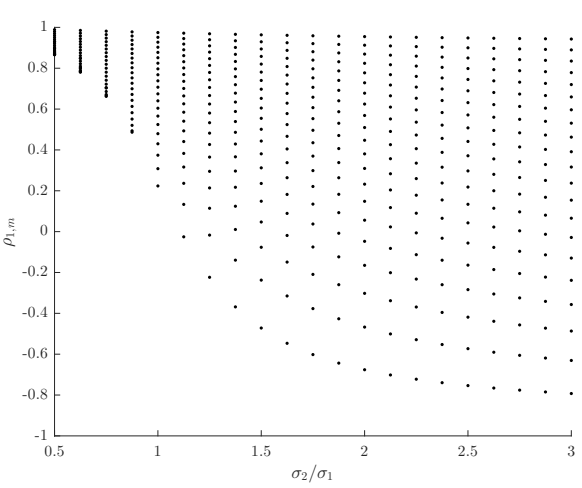

(c) $\rho_{1, m}$ depending on $\sigma_{2} / \sigma_{1}$.

The correlation between the returns of financial firm 1 and the financial system is shown as a function of the ratio of standard deviations and the correlation between institutions (Figure 3.a).

The correlation of returns between the financial institutions and the correlation between the returns of firm 1 and the financial market is not linear (Figure 3.b). The higher is the correlation between firms, the more probable would be having a positive correlation between financial firm 1 and the financial system. The relative standard deviation is a key parameter to determine the correlation between the returns of firm 1 and the financial market (Figure 3.c). The higher the variance of the returns of firm 1 in comparison to firm 2 is, the closer the correlation is to one.

The returns of the financial system are the equally weighted sum of the returns of the individual firms. 
Finally, Figure 4.a presents the weighted difference between $M E S_{1 \mid m}$ and $C o E S_{1 \mid m}$ for institution 1. Equation 12 proves that the sum of the weighted difference is zero, so we would have the opposite figure for institution 2 . The weighted difference would be positive if the returns of financial firm 1 present a higher variance than those coming from firm 2. The quantitative difference in absolute terms depending on which variable has a higher variance comes from the differences in level (Figure 4.c). On the one side, when the returns of firm 1 present twice the standard deviation of firm $2 \sigma_{1}=0.04$ and $\sigma_{2}=0.02$, so the weighted difference could be up to $3.3 \%$. On the other side, when the returns of firm 2 present twice the standard deviation of firm $1 \sigma_{1}=0.04, \sigma_{2}=0.08$ and the weighted difference could be up to $-4 \%$. The ratio between standard deviations determines the sign of the difference between $M E S_{1 \mid m}$ and $C o E S_{1 \mid m}$. A ratio higher than one implies a positive difference, whereas a ratio lower than one means a negative difference. Obviously, when the ratio between standard deviations is one the difference between $M E S_{1 \mid m}$ and $C o E S_{1 \mid m}$ is zero. This threshold would be different if $\omega_{1} \neq 0.5$.

The higher the correlation between financial institutions is, the more probable it is to have a weighted difference close to zero (Figure 4.b). A dispersion measure of the cross-section distribution of weighted difference provides an intuition about the possible level of dependence in the financial system. The lower the dispersion is, the higher the correlation could be. Indeed, there are two reasons why we could have a weighted difference equal to zero under this Gaussian framework. First, due to perfect correlation between both assets. Second, due to the equal variance of both financial firms (conditioned to an equally weighted composition of the financial system). Under the latter case, a lower dispersion measure would not be indicating a higher correlation between the institutions. The probability of the aggregate losses $\lambda$ could be helpful to distinguish between these two cases. Low dispersion in the weighted difference and a higher probability of occurrence indicate a high interdependence between the financial firms in the market. 
The weighted difference between $M E S_{1 \mid m}$ and $\operatorname{CoES}_{1 \mid m}$ depending on key parameters

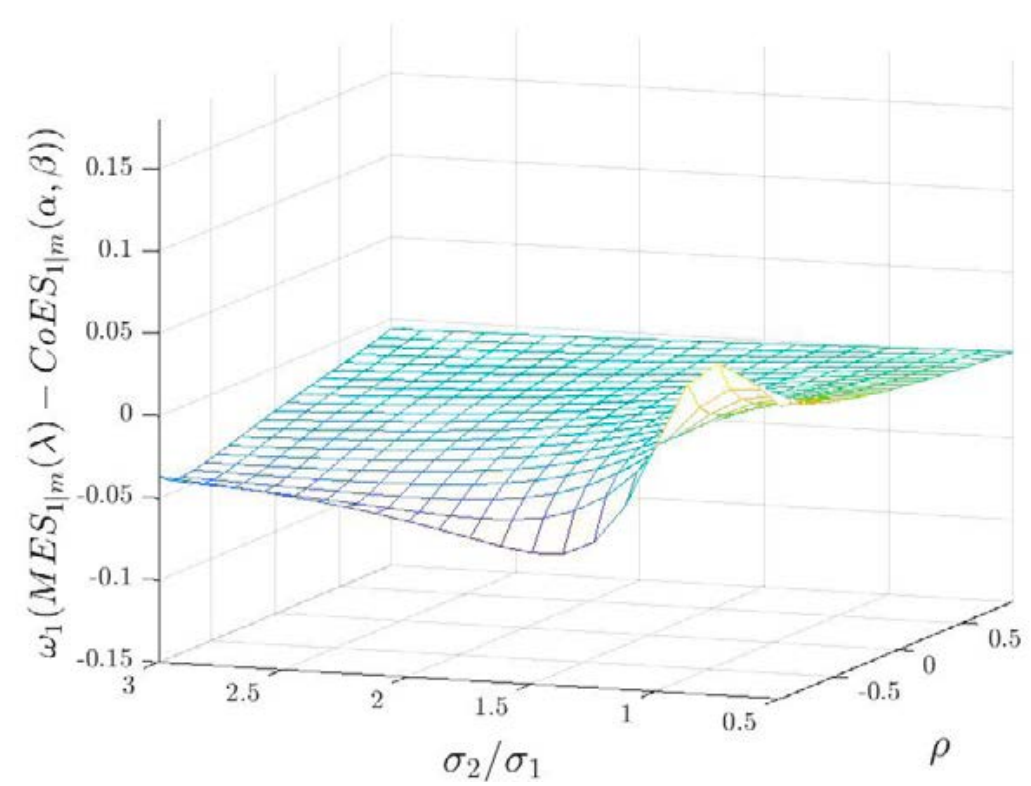

(a) $\omega_{1}\left(M E S_{1 \mid m}(\lambda)-\operatorname{CoES}_{1 \mid m}(\alpha, \beta)\right.$ depending on $\sigma_{2} / \sigma_{1}$ and $\rho$

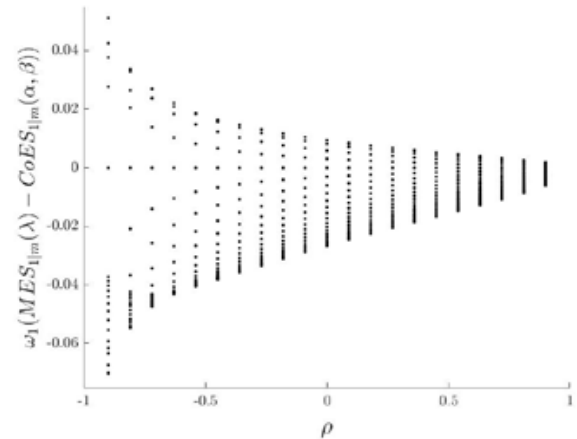

(b) $\omega_{1}\left(M E S_{1 \mid m}(\lambda)-\operatorname{CoES}_{1 \mid m}(a, \beta)\right.$ depending on $\rho$.

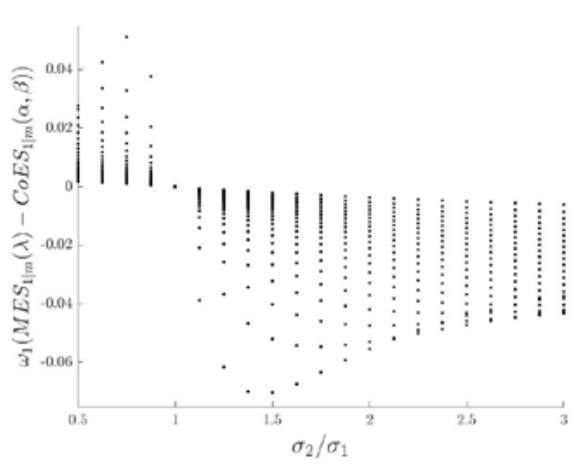

(c) $\omega_{1}\left(M E S_{1 \mid m}(\lambda)-\operatorname{CoES}_{1 \mid m}(\alpha, \beta)\right.$ depending on $\sigma_{2} / \sigma_{1}$

The weighted difference between MES and COES is shown as a function of the ratio of standard deviations and the correlation between institutions (Figure 4.a).

The sign of the relationship between the weighted difference between $M E S_{1 \mid m}$ and $\operatorname{CoES}_{1 \mid m}$ and the correlation between firm 1 and 2 is not defined (Figure 4.b), although the higher the correlation is, the closer the weighted difference is to zero. In case of negative correlation, values could be more extreme, while the sign depends on the relative standard deviation between institutions (Figure 4.c).

The returns of the financial system are the equally-weighted sum of the returns of the individual firms. 


\section{$5 \quad$ An empirical application to Spanish funds data}

This section applies the proposed model to real financial data from the Spanish mutual fund sector. The definition of the variable of interest and the relative importance of each firm, i.e., variables $r$ and $\omega$ in Equation (1), depends on the key systemic risks faced by the analysed sector. The FSB (2017) identifies the liquidity mismatch in investment funds as the main structural vulnerability in open-ended funds. The main risk is related to the potential redemption withdrawals and their ability to meet those redemptions without selling illiquid assets that could generate losses for the investment fund and could trigger fire sales with potential impact on the overall financial sector (Braverman and Minca, 2018; Cont and Wagalath, 2016; Duarte and Eisenbach, 2015). Hence, $r_{i}$ would be the redemption faced by fund $i$ and $\omega_{i}$ would be a measure of illiquidity of the fund $i$.

\subsection{Data}

This section presents in a first stage the different data sources that have been combined to build this unique and novel database. In a second stage it introduces how the measures of net flows and liquidity are computed. The biannual funds data about portfolio composition span the December 2008-December 2019 period, whereas the net flow data are computed weekly from 2 January 2009 to 26 June 2020.

The cleaning process of the dataset of mutual funds filters those funds that present some kind of restriction on redemptions and those funds in which their portfolio composition is not fully disclosed. ${ }^{3}$ Also, in order to have a balanced panel data, only those funds which have been active for the complete period 2009-2020 are considered.

Figure 5 shows the fund sample at the end of 2019 as a function of the liquidity of its portfolio (x-axis) and the assets under management (y-axis). The colour of each dot indicates the fund category. The dispersion regarding the liquidity widely varies from $10 \%$ to $80 \%$ while the size of the fund is between $€_{10}$ million and $€_{1}$ billion.

3 Appendix B.1 provides a detailed explanation on the types of funds which present a particular redemption policy and the concept of portfolio disclosure. 


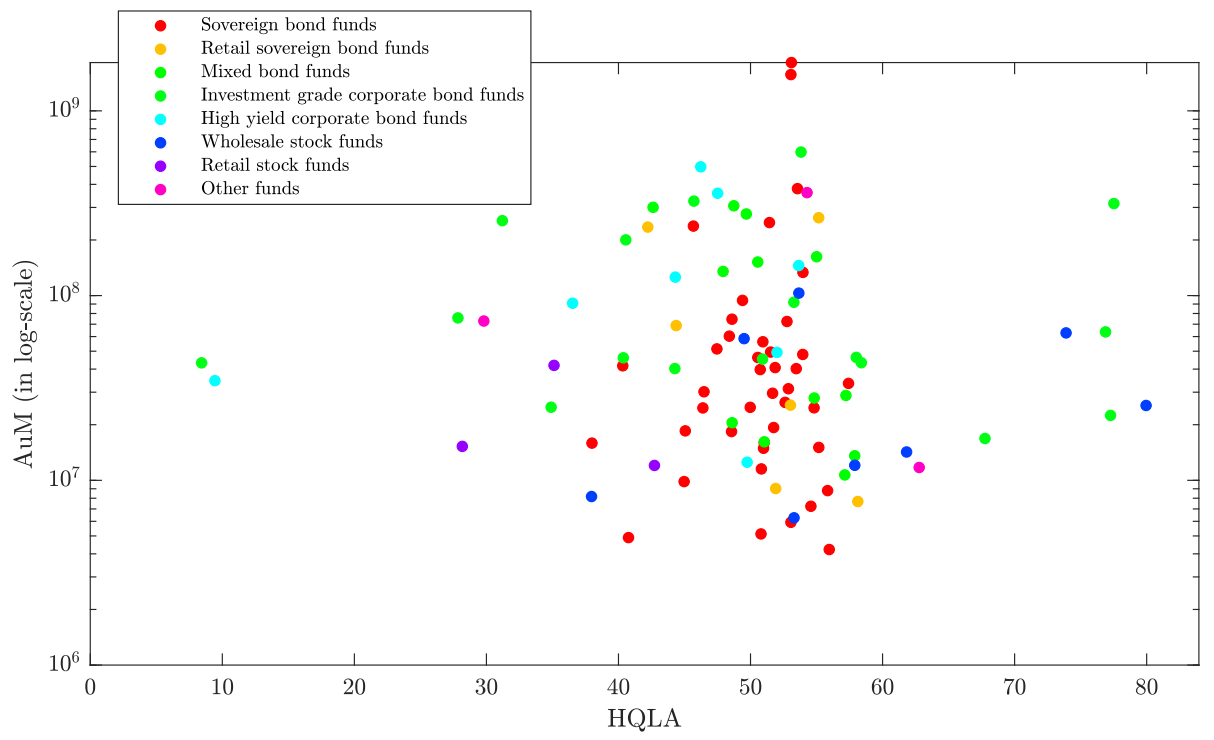

This figure shows the scatter plot of the fund sample showing on the x-axis the HQLA of the fund and in the $y$-axis the AuM in euros. The colour of each dot indicates the fund style according to different criteria. Appendix B.2 indicates the criteria to define a fund in a certain category.

\subsubsection{Data sources and sample construction}

The main source of data comes from the confidential information statements of undertakings for collective investment in transferable securities schemes, those identification codes are available at BOE (2008). The data regarding Net Asset Value (NAV) per share, Assets under Management (AuM) and dividends are obtained from statements MB2 and To1, while information in statement Mo4 provides the decomposition at a compartment level. The statement MB7 provides a decomposition of the fund's AuM by the amount invested by its participants. This statement is useful to classify each fund as retail or wholesale fund. ${ }^{4}$

Bloomberg ${ }^{5}$ and Thomson-Reuters ${ }^{6}$ databases are employed to identify the country, sector and rating ${ }^{7}$ of each position held by the fund, which is obtained from statement Mo4. This information is retrieved at the end of each semester and it allows for the classification of funds depending on features like credit quality of their assets. ${ }^{8}$ Also, the credit rating data are employed to build a liquidity index, i.e., the high-quality liquid assets that helps assess the resilience of investment funds to face

4 This study follows the approach employed by Cambon and Losada (2014) to define an investment fund as wholesale, i.e., those funds where investors holding more than $€ 150,000$ represent at least the $50 \%$ of the fund's AuM.

5 Fields employed: CNTRY OF RISK, CNTRY OF DOMICILE, INDUSTRY SECTOR, RTG MOODY, RTG SP, RTG FITCH, RTG MOODY ISSUER, RTG SP LT LC ISSUER CREDIT, and RGT FITCH LT ISSUER DEFAULT.

6 Fields employed: TR.FilssuerCountry, TR.HQCountryCode, TR.TRBCEconomicSector, TR.GR.Rating, and TR.IssuerRating.

7 Rating is considered the issue credit quality for bond assets or issuer credit quality for stock assets.

8 Importantly, the classification of funds at each semester is done with the information obtained from the previous semester. 
redemption scenarios. This approach is much more flexible than the classification provided by Morningstar, which is the database employed by ESMA (2019) for its simulation exercise using investment fund data, for two reasons. Firstly, Chen et al. (2019) have pointed to the existence of a bias in the Morningstar classification for mutual funds. According to the mentioned article, mutual funds systematically report a higher credit rating than the one expected from its portfolio composition in order to signal higher returns than expected. Secondly, our approach helps compute precisely the liquid positions in the investment funds because portfolio composition and credit quality information is gathered, while Morningstar database presents these sets of information separately.

\subsubsection{Measurement of the liquidity of investment funds}

At an individual level, the net flow of fund $i$ is obtained from the AuM time series. First, the return $R_{i, t}$ of the fund from the NAV per share $\left(N A V_{i, t}\right)$, i.e.

$$
R_{i, t}=\frac{N A V_{i, t}-N A V_{i, t-1}}{N A V_{i, t-1}} .
$$

is obtained. Second, the net flows measured as a ratio of AuM are obtained from the adjustment of the change in the AuM of the fund from $t-1$ to $t$ given the returns $R_{i, t}$ that the fund has obtained between $t-1$ to $t$, i.e.

$$
r_{i, t}=\frac{A u M_{i, t}-A u M_{i, t-1}\left(1+R_{i, t}\right)}{A u M_{i, t-1}} .
$$

Consequently, Equation (13) presents the variable $r_{i}$ in Equation (1).

A measure of liquidity of investment funds has to be set in order to estimate the resilience of funds to redemption shocks. This study follows the liquidity bucket approach, where each asset class in the fund portfolio is classified in buckets which have different degrees of liquidity. ESMA (2015) employs the High-Quality Liquid Assets (HQLA) approach, where a liquidity index is obtained by the weighted sum of the assets of the fund and the weight depends on the bucket in which each asset class is set, i.e.

$$
H Q L A=\sum_{k=1}^{n} w_{k} x s_{k}
$$

where $w_{k}$ is the liquidity weight for asset $k$ and $s_{k}$ is the share of asset $k$ as a percentage of the AuM. The haircuts applied to financial assets in stressed conditions provide an economic interpretation of the liquidity weights. The liquidity weights employed in this study are taken from ESMA (2019) and can be checked in Table 1. 
$\%$

\begin{tabular}{lrrrr}
\hline Asset class & CQS1 & CQS2 & CQS3 & $<$ CQS3 \\
\hline Government bonds & 100 & 85 & 50 & 0 \\
\hline Corporate & 85 & 50 & 50 & 0 \\
\hline Securitised & 65 & 0 & 0 & 0 \\
\hline Equities & 50 & 50 & 50 & 50 \\
\hline Cash & 100 & 100 & 100 & 100
\end{tabular}

Note: CQS: credit quality step. CQS1 refers to $A A A$ to $A A$ ratings, CQS2 to $A$ ratings, $C Q S 3$ to $B B B$ ratings, and $<$ CQS3 to any rating below BBB-. Liquidity weights are shown in \%.

Source: ESMA (2019) and (ESMA, 2015, p. 37).

It is worth noting that the combination of different databases provides a higher granularity that helps assess the HQLA in a very precise way. Table 2 presents an example of the portfolio composition and credit quality in an investment fund of the sample. ESMA (2019) has access to the portfolio composition and the credit quality separately, so they assume that the credit quality is uniformly distributed across each asset class. This implies that they are using only the last column and the last row from Table 2. The detailed information obtained from the financial statements, where the International Securities Identification Numbering (ISIN) code of each asset is available, combined with the credit quality of those assets taken from Bloomberg and Thomson-Reuters databases, helps build an in-depth view of the liquid assets held by Spanish investment funds. Using all the information in the table a HQLA of $37.4 \%$ is obtained, while using the available information in the ESMA (2019) Economic Report the corresponding value is $29.9 \%$.

\section{Example of the composition of a fund portfolio}

$\%$

\begin{tabular}{lrrrrr}
\hline & Sovereign debt & Corporate debt & Equity & Cash & Total \\
\hline CQS1 & 0.0 & 0.0 & - & - & 2.0 \\
\hline CQS2 & 2.2 & 17.0 & - & - & 21 \\
\hline CQS3 & 3.0 & 34.1 & 0.0 & 8.5 & 39 \\
\hline$<$ CQS3 & 1.5 & 33.8 & - & - & 37 \\
\hline Total & 6.7 & 84.9 & 0.0 & 8.5 & 100 \\
\hline
\end{tabular}

Note: CQS: credit quality step. CQS1 refers to $A A A$ to $A A$ ratings, CQS2 to $A$ ratings, CQS3 to $B B B$ ratings, and $<$ CQS3 to any rating below BBB-. Liquidity weights are shown in \%.

This table shows an example of the composition of a fund portfolio and the implications that the higher granular data has for the assessment of HQLA. To compute the HQLA we use the weights in Table 1.

ESMA only can get the information from the last column and last row computing a HQLA equal to $29.9 \%$, while using all the information provides a HQLA equal to $37.4 \%$.

To get the values of $\omega$ in Equation (1), we use the AuM weighted by the illiquidity of the fund portfolio, which is defined as $100-H Q L A$. In other words, $\omega_{i}$ is defined as

$$
\omega_{i}=\frac{A u M_{i}\left(100-H Q L A_{i}\right)}{\sum_{i=1}^{N} A u M_{i}\left(100-H Q L A_{i}\right)} .
$$




\subsection{Methodology}

To perform the empirical exercise, a non-parametric method is used based on a kernel smoothing function copula using a normal kernel. The normal kernel function provides the distribution of the funds flows, while for the flows of the financial system, the kernel function is combined with a Pareto tail distribution below quantile $5_{\text {-th }}$ and above quantile $95^{\text {-th }}$ to meet possible tail behaviour. The next codes summarise the procedure followed to get the results from a simulation process.

In order to get time-varying features, the kernel function is built using the net flows from the last six semesters and the weight employed is the one from the previous semester. For instance, to analyse the systemic risk of the fund sector in the first semester of 2020, the distribution and dependence between flows is obtained using the kernel function on the weekly net flows from the first semester of 2017 to the first semester of 2020. The weights are obtained from the AuM and the HQLA of the funds in the second semester of 2019 .

\footnotetext{
Algorithm 1

Algorithm to simulate realisations from the joint distribution

for $k \leftarrow N$ do

$\triangleright$ Get marginal distribution

2: $U_{k}=F_{k}\left(r_{k}\right)$

end for $k$

4: $\quad U_{m}=F_{m}\left(\sum_{k}^{N} \omega_{k} r_{k}\right)$

$\triangleright$ Build target variable

for $k \leftarrow N$ do

$\triangleright$ Get dependence to the financial system

6: $C_{m, k}\left(U_{k}, U_{m}\right)$

end for $k$
}

8: for $w \leftarrow W$ do

$\triangleright$ Now the simulation process starts

$v_{m, w}=\operatorname{rand} * \alpha$

$\triangleright$ The financial system is below its $\alpha$ 100-th quantile

10: for $k \leftarrow N$ do

$v_{k, w}=C_{m, k}^{-1}\left(\operatorname{rand} \mid v_{m, w}\right)$

$\triangleright$ Use the inverse conditional copula. See Joe (2014)

12: $\tilde{r}_{k, w}=F_{k}^{-1}\left(v_{k, w}\right)$

end for $k$

14: end for $w$

$F k$ is the kernel smoothing function for firm $k$, while $F_{m}$ is the kernel smoothing function for the financial system. See Bowman and Azzalini (1997). rand refers to the realization of a uniform distribution $(0,1)$. W refers to the number of simulations. $\omega_{k} \in[0,1]$ is the weight associated with the individual mutual fund $k$ such that $\sum_{k} w_{k}=1$.

Csystem, $k$ (Uk, Usystem) is estimated using the bivariate kernel smoothing function. 
Algorithm 2

Computing risk measures from the simulated net flows

for $k \leftarrow N$ do

2: $\operatorname{CoVaR}(1, k)=\max \left(\tilde{r}_{k, 1: W}\right.$ such that $\left.\#\left\{r_{k, 1: W} \leq \operatorname{CoVa} R_{k}\right\}=\operatorname{round}(W \beta)\right)$

$\operatorname{CoE} S_{k}=\left(\sum_{w=1}^{W} \tilde{r}_{k, w} \mathbb{1}_{\tilde{r}_{k, w}<\operatorname{CoVaR}}\right) /\left(\sum_{w=1}^{W} \mathbb{1}_{\tilde{r}_{k, w}<\operatorname{CoVaR} R_{k}}\right)$

4: $\quad$ end for $i$

$E S_{\lambda}=\sum_{k}\left(\omega_{k} C o E S_{k}\right)$

6: $\lambda=q$ such that $E S_{\lambda}=E\left(r_{m} \mid r_{m}<F_{m}{ }^{-1}(q)\right)$

round is a function that rounds to the nearest integer.

$M E S_{\lambda}$ is obtained computing the mean of the simulated returns from Algorithm 1 by changing $\alpha$ for $\lambda$.

$\mathbb{1}_{A}$ is an indicator function that values 1 if the condition $A$ is met and zero otherwise.

\subsection{Results}

This section summarizes the main results. Firstly, we present the outcomes from our methodology. Afterwards, we compare the fund ranking according to different risk measures and indicators, which help us to identify the kind of information gathered in our methodology. In order to perform the simulation procedure, the distress scenario is defined as being below median values, i.e. parameters $\alpha$ and $\beta$ are set equal to 0.5 .

To begin with, the Expected Shortfall obtained from Equation (11) and its associated probability $(\lambda)$ is shown in Figure 6.a. The Expected Shortfall presents a decreasing trend until the second semester of 2014, then it experiences an increase in 2015 and the decreasing trend continues until the end of the sample. The probability of the mean losses provided by the Expected Shortfall are quite low, below 1\% for all the considered period.

The cross section contribution, i.e. $\omega(M E S(\lambda)-\operatorname{CoES}(\alpha, \beta))$, is computed for the individual funds and then they are summed across those funds which are within the same fund category. ${ }^{9}$ Using this information four periods can be identified in the data set. The first period, up to the second semester of 2014, where the systemic risk is led by the sovereign fund category, which coincides with the European sovereign debt crisis. From the first semester of 2015 to the second semester of 2017 , high yield and wholesale stock categories lead the systemic risk within the mutual fund sector. From the second semester of 2017 to the second semester of 2019 the sovereign category, in particular wholesale sovereign funds, is the one that contributes most to systemic risk. Finally, the retail stock and the high yield category are the main contributors to systemic risk in the last two semesters of the sample. This increasing role of fund categories investing in corporate assets to build the systemic risk indicators could be related to the COVID-19 crisis.

9 Detailed information about the criteria to set a fund in certain fund category is shown in Appendix B.2. 


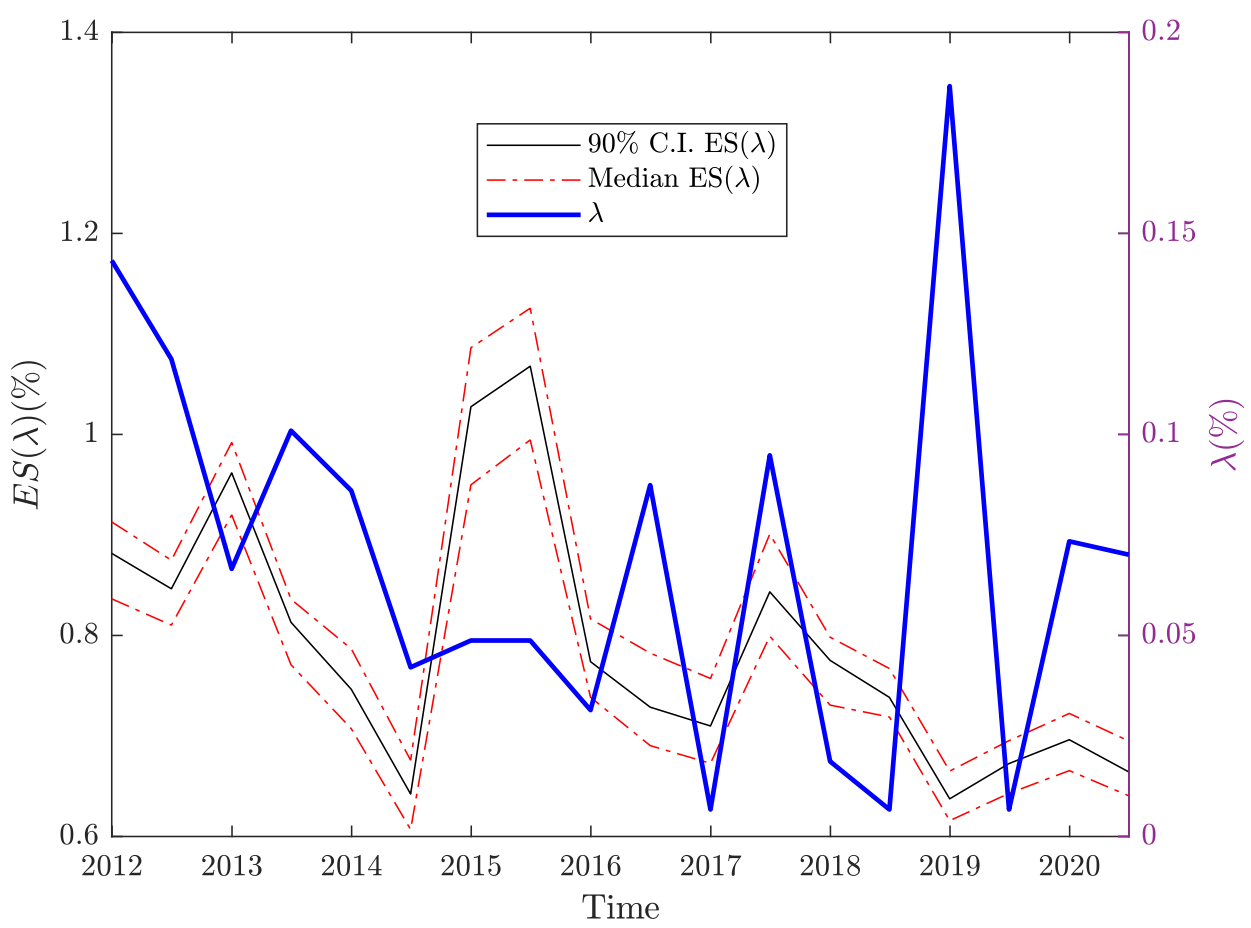

(a) Time series information: $E S(\lambda)$ and $\lambda$.

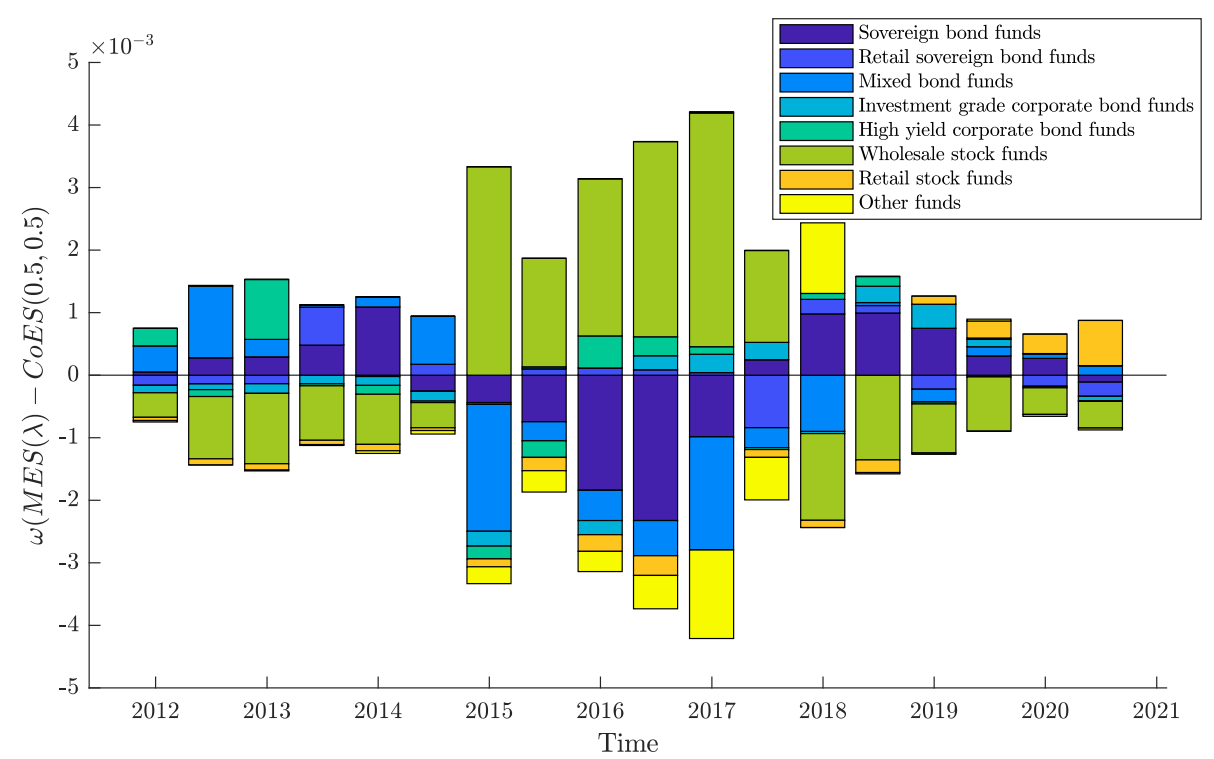

(b) Cross section information: $\omega(M E S(\lambda)-\operatorname{CoES}(\alpha, \beta))$.

The top subplot (Figure 6.a) shows the time series information about the aggregate systemic risk within the fund sector using parameters $\alpha=\beta=0.5$. Both the aggregate losses and the probability associated to those losses decreases from 2015 onwards. Confidence intervals are generated by simulation. The bottom subplot (Figure 6.b) indicates the weighted difference between $\operatorname{MES}(\lambda)$ and $\operatorname{CoES}(\alpha, \beta)$ of the funds aggregated by investment style. Further information regarding the classification of the funds can be found in Appendix B.2. 
Figure 7 shows the systemic risk contribution using the CES of Banulescu and Dumitrescu (2015) for each fund and then the values have been aggregated by fund style. ${ }^{10}$ It can be distinguished in the figure the main four periods that have been indicated in Figure 6.b. However, the CES measure presents two main disadvantages compared to our approach. Firstly, the scale is changing over time as the Expected Shortfall evolves, so the cross-section contribution at $t$ cannot be properly compared to the cross-section contribution at $t-1$. The approach in this paper is scale invariant, so the contribution of each category at time $t$ does not depend on any time series variable but on the relative performance of the remainder funds on that time. Secondly, although CES allows to distinguish between funds that contribute and funds that absorb risk, e.g. for 2014-2018 we have fund categories with positive and negative contributions, we cannot divide the fund sample to distinguish those funds which deserve a higher attention.

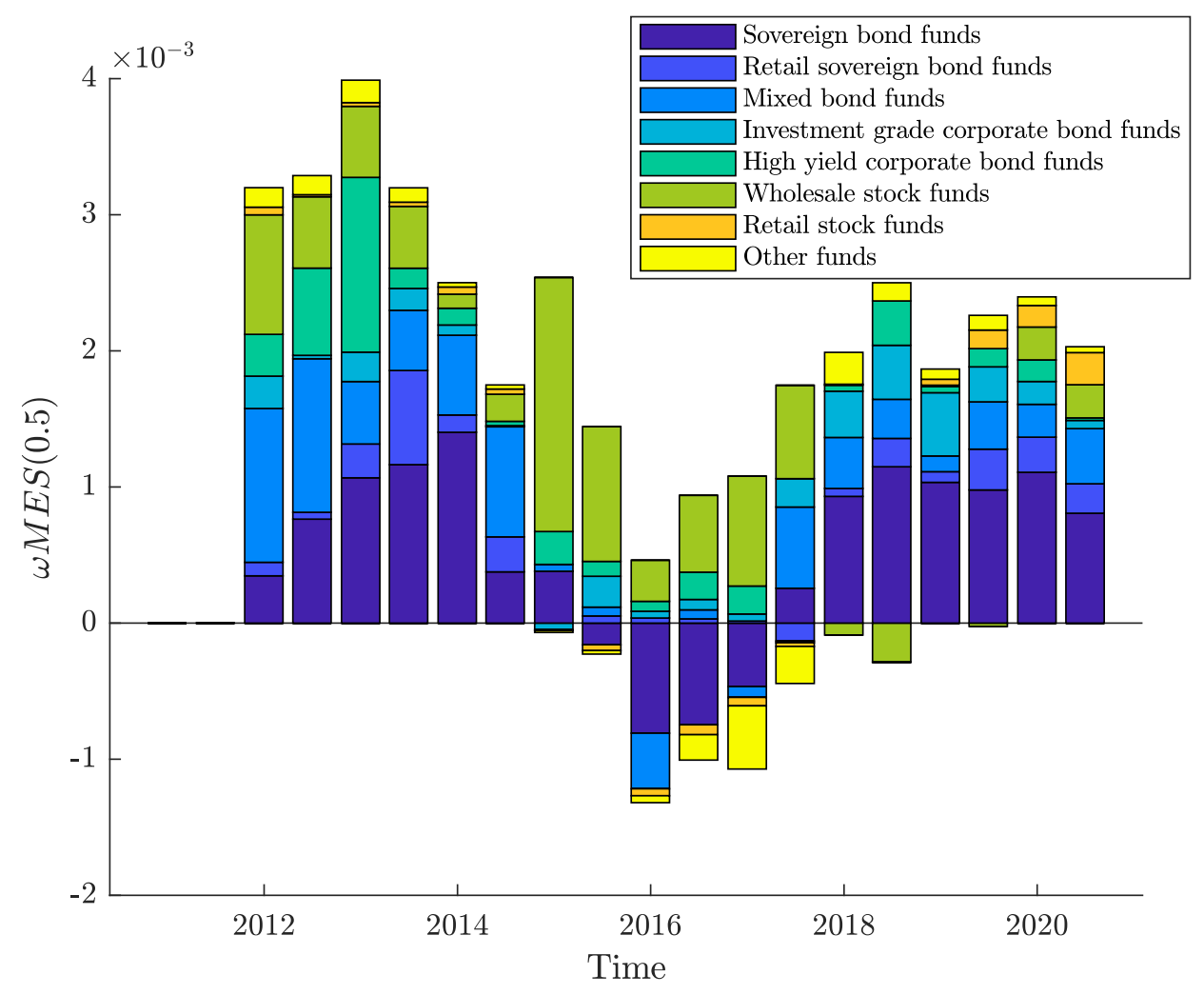

This figure indicates the weighted $M E S(\alpha)$ of the funds aggregated by investment style. Note that other measures like $M E S$ of $\triangle C O E S_{m \mid i}$ do not allow to aggregate individual measures in groups. Further information regarding the classification of the funds can be found in Appendix B.2.

Table 3 provides the identification code that ensures the anonymity of the ten funds which present a highest risk measure or indicator to compare how much our ranking meets other criteria of performance. The last row indicates how many 
funds are shared with our ranking in the top ten funds according to those criteria. The matching reaches the 60\% with the CES measure of Banulescu and Dumitres$\mathrm{cu}(2015)$ and a $50 \%$ if the size of the fund is looked at, whereas it shows a $30-20 \%$ of common funds with the remainder measures or indicators. More information about the sector, the liquidity and the size of the funds in the top ten is shown in Table 4 .

Ranking according to $\omega$ (COES - MES)

TABLE 3

\begin{tabular}{|c|c|c|c|c|c|c|}
\hline Ranking & $\omega(M E S-C o E S)$ & CES & MES & $\Delta \operatorname{CoES}_{m \mid i}$ & HQLA & AuM \\
\hline $1^{\text {st }}$ & 12 & 10 & 80 & 12 & 65 & \\
\hline $2^{\text {nd }}$ & 37 & 37 & 62 & 80 & 80 & \\
\hline $3^{\text {rd }}$ & 10 & 53 & 19 & 69 & 60 & \\
\hline $4^{\text {th }}$ & 63 & 84 & 43 & 70 & 74 & \\
\hline $5^{\text {th }}$ & 43 & 80 & 61 & 63 & 72 & \\
\hline $6^{\text {th }}$ & 87 & 12 & 46 & 68 & 84 & \\
\hline $7^{\text {th }}$ & 84 & 61 & 88 & 59 & 70 & \\
\hline $8^{\text {th }}$ & 80 & 97 & 64 & 57 & 94 & \\
\hline $9^{\text {th }}$ & 97 & 6 & 40 & 5 & 67 & \\
\hline \multirow[t]{2}{*}{$10^{\text {th }}$} & 31 & 78 & 37 & 38 & 82 & \\
\hline & $100 \%$ & $60 \%$ & $30 \%$ & $30 \%$ & $20 \%$ & \\
\hline
\end{tabular}

Note: The identification code that ensures the anonymity of the funds is shown in each column for the 10-highest systemic risk measures. The risk measures are our proposed ranking ( $\omega(M E S-C O E S))$, the Component Expected Shortfall $(C E S(0.5))$, the Marginal Expected Shortfall $(M E S(0.5))$, the Delta $\operatorname{CoES}\left(\triangle \operatorname{CoES} S_{m \mid i}(0.5,0.5)\right.$ under the definition of Girardi and Ergün (2013)) and the HQLA and the AuM of each fund.

The HQLA is shown in \%. The AuM is shown in millions of euros.

The risk measures are computed at the end of June 2020. The HQLA and the AuM are shown at the end of 2019.

The last row indicates the percentage of funds in the top ten which are common to our ranking. The weight $(\omega)$ is obtained from Equation (15). 


\begin{tabular}{llrr}
\multicolumn{3}{c}{$\omega$ (MES - COES) } \\
\hline Fund & Sector & HQLA & AuM \\
\hline 12 & Retail stock funds & 48.74 & 306.23 \\
\hline 37 & Sovereign bond funds & 45.71 & 324.66 \\
\hline 10 & Sovereign bond funds & 53.83 & 598.16 \\
\hline 63 & Wholesale stock funds & 53.10 & 1825.32 \\
\hline 43 & Wholesale stock funds & 52.76 & 72.40 \\
\hline 87 & Mixed bond funds & 53.65 & 145.41 \\
\hline 84 & Sovereign bond funds & 31.21 & 254.39 \\
\hline 80 & Mixed bond funds & 9.44 & 34.63 \\
\hline 97 & Mixed bond funds & 47.51 & 358.04 \\
\hline \multirow{3}{*}{31} & Retail stock funds & & \\
\hline & & 42.62 & 300.47 \\
\hline
\end{tabular}

\begin{tabular}{llrr}
\multicolumn{4}{c}{$\Delta$ CoES $_{\boldsymbol{m} \mid \boldsymbol{i}}$} \\
\hline Fund & Sector & HQLA & AuM \\
\hline 12 & Retail stock funds & 48.74 & 306.23 \\
\hline 80 & Mixed bond funds & 9.44 & 34.63 \\
\hline 69 & Sovereign bond funds & 58.39 & 43.31 \\
\hline 70 & Sovereign bond funds & 34.90 & 24.87 \\
\hline 63 & Wholesale stock funds & 53.10 & 1825.32 \\
\hline 68 & Wholesale stock funds & 50.55 & 46.24 \\
\hline 59 & Wholesale stock funds & 50.94 & 56.23 \\
\hline 57 & Sovereign bond funds & 58.01 & 46.28 \\
\hline 5 & Investment grade corporate & 42.22 & 234.85 \\
& bond & & \\
\hline 38 & Wholesale stock funds & 53.96 & 48.02 \\
\hline & & &
\end{tabular}

\begin{tabular}{llcc}
\hline Fund & Sector & HQLA & AuM \\
\hline 10 & Sovereign bond funds & 53.83 & 598.16 \\
\hline 37 & Sovereign bond funds & 45.71 & 324.66 \\
\hline 53 & Retail sovereign bond funds & 54.28 & 360.81 \\
\hline 84 & Sovereign bond funds & 31.21 & 254.39 \\
& & & \\
\hline 80 & Mixed bond funds & 9.44 & 34.63 \\
\hline 12 & Retail stock funds & 48.74 & 306.23 \\
\hline 61 & Sovereign bond funds & 77.52 & 314.85 \\
\hline 97 & Mixed bond funds & 47.51 & 358.04 \\
& & & \\
\hline 6 & Wholesale stock funds & 53.06 & 1571.44 \\
\hline 78 & Wholesale stock funds & 51.43 & 248.39 \\
\hline & & & \\
\hline
\end{tabular}

\begin{tabular}{llrr}
\hline Fund & Sector & HQLA & AuM \\
\hline 65 & Sovereign bond funds & 8.43 & 43.24 \\
\hline 80 & Mixed bond funds & 9.44 & 34.63 \\
\hline 60 & Sovereign bond funds & 27.84 & 75.70 \\
\hline 74 & High yield corporate bond & 28.18 & 15.27 \\
& funds & & \\
\hline 72 & Retail sovereign bond funds & 29.81 & 72.82 \\
\hline 84 & Sovereign bond funds & 31.21 & 254.39 \\
\hline 70 & Sovereign bond funds & 34.90 & 24.87 \\
\hline 94 & High yield corporate bond & 35.12 & 41.90 \\
& funds & & \\
\hline 67 & Mixed bond funds & 36.53 & 90.91 \\
\hline 82 & Other funds & 37.96 & 8.17 \\
\hline & & & \\
\hline
\end{tabular}

\begin{tabular}{llrr}
\hline Fund & Sector & HQLA & AuM \\
\hline 80 & Mixed bond funds & 9.44109 & 34.62832 \\
\hline 62 & Other funds & 73.8962 & 62.79962 \\
\hline 19 & Wholesale stock funds & 54.5729 & 7.239257 \\
\hline 43 & Wholesale stock funds & 52.761 & 72.40415 \\
\hline 61 & Sovereign bond funds & 77.5181 & 314.8527 \\
\hline 46 & Other funds & 79.9552 & 25.42115 \\
\hline 88 & Wholesale stock funds & 52.8696 & 31.31498 \\
\hline 64 & Wholesale stock funds & 51.6707 & 29.60354 \\
\hline 40 & Sovereign bond funds & 67.756 & 16.84379 \\
\hline 37 & Sovereign bond funds & 45.7126 & 324.6636 \\
\hline
\end{tabular}

\begin{tabular}{llrr}
\hline Fund & Sector & HQLA & AuM \\
\hline 63 & Wholesale stock funds & 53.0966 & 1825.318 \\
\hline 6 & Wholesale stock funds & 53.0591 & 1571.441 \\
\hline 10 & Sovereign bond funds & 53.8268 & 598.1555 \\
\hline 93 & Mixed bond funds & 46.2316 & 497.7008 \\
\hline 4 & Wholesale stock funds & 53.5572 & 379.1799 \\
\hline 53 & Retail sovereign bond funds & 54.2797 & 360.8065 \\
\hline 97 & Mixed bond funds & 47.508 & 358.0366 \\
\hline 37 & Sovereign bond funds & 45.7126 & 324.6636 \\
\hline 61 & Sovereign bond funds & 77.5181 & 314.8527 \\
\hline 12 & Retail stock funds & 48.7351 & 306.2278 \\
\hline
\end{tabular}

Note: The identification code that ensures the anonymity of the funds is shown in the first column of each subtable for the 10-highest systemic risk measures. The risk measures are our proposed ranking $(\omega(M E S-$ COES)), the Component Expected Shortfall (CES(0.5)), the Marginal Expected Shortfall $(M E S(0.5))$, the Delta CoES $\left(\triangle \operatorname{CoES}_{m \mid i}(0.5,0.5)\right.$ under the definition of Girardi and Ergün (2013)) and the HQLA and the AuM of each fund. The HQLA is shown in \%. TheAuM is shown in millions of euros.

The risk measures are computed at the end of June 2020. The HQLA and the AuM are shown at the end of 2019. The table shows the HQLA, the AuM and the sector of each fund in the top ten ranking. Information about the set of sectors within the mutual fund universe are explained in detail in Appendix B.2. 


\section{Conclusions}

This article introduces a new methodology to quantify the losses coming from systemic risk, compute its probability of occurrence and the role of each institution within the financial sector. The flexibility of the methodology holds on statistical concepts coming from the Expected Shortfall and the freedom to choose those weights that better explain the features that could trigger a systemic event in a certain sector.

This methodology provides a comprehensive view about systemic risk through the connection between financial firms and the proxy for the financial market. The quantification and its probability of occurrence shed light about the consequences of stronger dependence and higher variance in the variables of interest for financial firms. The ranking obtained from the weighted difference between its marginal behaviour and its tail performance provides a threshold around zero in order to distinguish those institutions that present a higher risk than the overall financial sector. The empirical exercise using Spanish investment fund data shows that the ranking following the proposed approach is different from the one obtained by other risk measures like the $M E S$ or the $\triangle C o E S$. Also, it provides more relevant information for the identification of particular firms in the cross section than the CES.

Further research should be performed regarding key variables in the balance sheet or the portfolio composition that could determine the weights for the financial institutions into the financial sector. Depending on the sector of the financial industry, the key features to take into account would be different and should be linked to the potential risk of financial firms. For instance, from a macroprudential point of view, relative weights of bank size over the domestic GDP could help to underline the D-SIB role in the EU economy. Also, the leverage ratio could be a rule of thumb to choose the weights for the banking subsector. The fire sales and the potential price impact are the main systemic risks coming from the investment fund sector (ESMA, 2019). Systemic measures could provide insightful intuition about the firms to be closely supervised. In order to reach this goal, the right weights should be chosen based on liquidity measures and $N A V$ to mimic the behaviour of the investment fund sector in case of fire sales in financial markets. Also, future extensions could study the systemic risk methodology presented here using some parametric models that take into account the joint skewness and kurtosis of the distribution, e.g. the Skewed- $t$ copula (see Jaworski et al., 2010; Lucas et al., 2014).

The findings of this piece of research have implications for policy makers and market supervisors, allowing them to obtain relevant information about the magnitude and probability of the losses in a distress scenario. Besides, the ranking provides some insightful intuition about which are the main institutions from where these losses could come. 



\section{References}

Acerbi, C. and Tasche, D. (2002). "On the coherence of Expected Shortfall". Journal of Banking and Finance, Vol. 26, pp. 1487-1503.

Acharya, V., Engle, R. and Richardson, M. (2012). "Capital shortfall: A new approach to ranking and regulating systematic risks". American Economic Review, Vol. 102, No. 3, pp. 59-64.

Adrian, T. and Brunnermeier, M. K. (2016). "CoVaR". The American Economic Review, Vol. 106, No. 7, pp. 1705-1741.

Artzner, P., Delbaen, F., Eber, J. M. and Heath, D. (1999). "Coherent measures of risk". Mathematical finance, Vol. 9, No. 3, pp. 203-228.

Banulescu, G. D. and Dumitrescu, E. I. (2015). "Which are the SIFIs? A component expected shortfall approach to systemic risk". Journal of Banking \& Finance, Vol. 50, pp. $575^{-588 .}$

Benoit, S., Colletaz, G., Hurlin, C. and Pérignon, C. (2013). A Theoretical and Empirical Comparison of Systemic Risk Measures. Working Papers halshs-00746272, HAL.

Benoit, S., Colliard, J. E., Hurlin, C. and Pérignon, C. (2017). "Where the risks lie: A survey on systemic risk”. Review of Finance, Vol. 21, No.1, pp. 109-152.

Bernanke, B. (2009). "Financial Reform to Address Systemic Risk". Speech delivered at the Council on Foreign Relations.

Bernanke, B. (2010). "Causes of the Recent Financial and Economic Crisis". Statement of the FED Chairman before the Financial Crisis Inquiry Commission.

Bernard, C., Brechmann, E. C. and Czado, C. (2013). "Statistical assessments of systemic risk measures”. Handbook on Systemic Risk, pp. 165-179.

BOE (2008). Circular 3/2008, de 11 de septiembre, de la Comisión Nacional del Mercado de Valores sobre normas contables, cuentas anuales y estados de información reservada de las instituciones de inversión colectiva.

Boot, A. W. A. and Ratnovski, L. (2012). Banking and Trading. CEPR Discussion Papers, No. 9148, C.E.P.R. Discussion Papers.

Bowman, A. and Azzalini, A. (1997). Applied Smoothing Techniques for Data Analysis: The Kernel Approach with S-Plus Illustrations, Volume 18. OUP Oxford. 
Braverman, A. and Minca, A. (2018). "Networks of common asset holdings: aggregation and measures of vulnerability". The Journal of Network Theory in Finance, Vol. 4, No. 3 .

Brownlees, C. and Engle, R. F. (2016). "Srisk: A conditional capital shortfall measure of systemic risk". The Review of Financial Studies, Vol. 30, No. 1, pp. 48-79.

Burzoni, M., Peri, I. and Ruffo, C. M. (2017). "On the properties of the lambda value at risk: robustness, elicitability and consistency". Quantitative Finance, Vol. 17, No. 11 , pp. 1735- 1743 .

Cambon, M. I. and Losada, R. (2014). "Competition and structure of the mutual fund industry in Spain: The role of credit institutions”. The Spanish Review of Financial Economics, Vol. 12, No. 2, pp. 58-71.

Chen, H., Cohen, L. and Gurun, U. (2019). Don't take their word for it: The misclassification of bond mutual funds. National Bureau of Economic Research, Technical Report.

Chen, K. H. and Khashanah, K. (2014). Measuring systemic risk: Copula CoVaR. Stevens Institute of Technology, Technical report.

Constâncio, V. (2017). "Macroprudential stress-tests and tools for the non-bank sector". ESRB Annual Conference.

Cont, R. and Wagalath, L.(2016). "Institutional investors and the dependence structure of asset returns". International Journal of Theoretical and Applied Finance, Vol. 19, No. 02.

Duarte, F. and Eisenbach, T. (2015). Fire-sale spillovers and systemic risk. Staff Report No. 645. Technical report.

ECB (2010a). Analytical models and tools for the identification and assessment of systemic risks. Financial Stability Review, Technical report. June.

ECB (2010b). New quantitative measures of systemic risk. Financial Stability Review, Technical report. December.

ESMA (2015). Report on trends, risks and vulnerabilities. Technical Report No. 2.

ESMA (2019). Stress simulation for investment funds. Economic Report.

Farhi, E. and Tirole, J. (2012). "Collective Moral Hazard, Maturity Mismatch, and Systemic Bailouts”. American Economic Review, Vol. 102, No. 1, pp. 60-93.

Ferreiro, J. O. (2018). Contagion spillovers between sovereign and financial European sector from a delta CoVaR approach. Universidad Complutense de Madrid, Facultad de Ciencias Económicas y Empresariales, ICAE Working Papers No. 2018-12. 
Frittelli, M., Maggis, M. and Peri, I. (2014). "Risk measures on and value at risk with probability/loss function". Mathematical Finance, Vol. 24, No. 3, pp. 442-463.

FSB (2017). Transforming shadow banking into resilient market-based finance: Rehypothecation and collateral re-use: Potential financial stability issues, market evolution and regulatory approaches. Technical Report. January.

Girardi, G. and Ergün, A. T. (2013). "Systemic risk measurement: Multivariate GARCH estimation of CoVaR". Journal of Banking and Finance, Vol. 37, No. 8, pp. 3169-3180.

Guntay, L. and Kupiec, P. (2014). Taking the risk out of systemic risk measurement. American Enterprise Institute (AEI) Research Paper, Technical Report.

Hitaj, A., Mateus, C. and Peri, I. (2018). "Lambda value at risk and regulatory capital: A dynamic approach to tail risk”. Risks, Vol. 6, No. 1, p. 17.

International Monetary Fund, Bank for International Settlements, and Financial Stability Board (2010). "Guidance to assess the systemic importance of financial institutions, markets and instruments: Initial considerations: Report to the G-20 Finance Ministers and Central Bank Governors". Staff of the International Monetary Fund and the Bank for International Settlements, and the Secretariat of the Financial Stability Board.

Jaworski, P., Durante, F., Hardle, W. K. and Rychlik, T. (2010). Copula theory and its applications, Vol. 198. Springer.

Joe, H. (2014). Dependence Modeling with Copulas. Chapman and Hall/CRC.

Kleinow, J., Moreira, F., Strobl, S. and Vähämaa, S. (2017). "Measuring systemic risk: A comparison of alternative market-based approaches". Finance Research Letters, Vol. 21, pp. 40-46.

Laeven, L., Ratnovski, L. and Tong, H. (2014). "Bank Size and Systemic Risk". IMF Staff Discussion Notes 14/4, International Monetary Fund.

Leon Li, M. Y. and Lin, H. W. (2004). "Estimating value-at-risk via Markov switching arch models - An empirical study on stock index returns". Applied Economics Letters, Vol. 11, No. 11, pp. 679-691.

Löffler, G. and Raupach, P. (2017). "Pitfalls in the use of systemic risk measures". Journal of Financial and Quantitative Analysis.

Lucas, A., Schwaab, B. and Zhang, X. (2014). "Conditional euro area sovereign default risk". Journal of Business \& Economic Statistics, Vol. 32, No. 2, pp. 271-284.

Mainik, G. and Schaanning, E. (2014). "On dependence consistency of CoVar and some other systemic risk measures”. Statistics and Risk Modeling, Vol. 31, No. 1, pp. 49-77. 
Rose, A. and Wieladek, T. (2012). Too big to fail: some empirical evidence on the causes and consequences of public banking interventions in the United Kingdom. Bank of England, Working Papers No. 460.

Salleo, C., Homar, T. and Kick, H. (2016). Making sense of the EU wide stress test: a comparison with the SRISK approach. European Central Bank, Working Paper Series No. 1920.

Scott, H. S., Ricci, K. and Sarfatti, A. (2016). SRISK as a Measure of Systemic Risk for Insurers: Oversimplified and Inappropriate. Harvard Law School, Working Paper.

Shleifer, A. and Vishny, R. W. (2009). Unstable Banking. National Bureau of Economic Research, Inc., NBER Working Papers No. 14943.

Trichet, J. C. (2009). "Clare Distinguished Lecture in Economics and Public Policy". Speech at University of Cambridge organised by the Clare College.

Zhang, J. (2015). Systemic Risk Measure: CoVaR and Copula. Ph. D. thesis, HumboldtUniversität zu Berlin. 


\section{Appendices}

\section{A Building systemic risk measures}

The expression for each measure is provided first in a general formula and then the particular one under the chosen methodology.

\section{A.1 Expected Shortfall (ES) of the financial market}

The $\operatorname{VaR}_{m}(\alpha)$ gives information about how large is the minimum return for the financial market $m$ with a $(1-\alpha) 100 \%$ confidence level. It is obtained by solving the implicit equation

$$
P\left[r_{m} \leq \operatorname{VaR}_{m}(\alpha)\right]=\alpha
$$

Expressing Equation (16) following the proposed model under Gaussian assumptions

$$
\operatorname{VaR}_{m}(\alpha)=\mu_{m}+\sigma_{m} \Phi^{-1}(\alpha)
$$

where $\Phi^{-1}$ is the inverse standardised cumulative Gaussian distribution function.

The Value-at-Risk only looks at a certain quantile, consequently it is not a subadditive measure. The properties of this risk measure can be enhanced if we look further than the quantile of interest for the VaR. The Expected Shortfall tells us how large are the average losses in the financial market if these losses are higher than $-\operatorname{VaR}(\alpha)$, i.e.,

$$
\begin{aligned}
E S_{m}(\alpha) & =\mathbb{E}_{m}\left[-r_{m} \mid r_{m}<\operatorname{VaR}(\alpha)\right] \\
& =\frac{1}{\alpha} \int_{0}^{\alpha}-\operatorname{VaR}_{m}(s) \quad d s
\end{aligned}
$$

where for the Gaussian case it is a closed form without computing numerically the integral

$$
E S_{m}(\alpha)=\sigma_{m} \alpha^{-1} \phi\left(\Phi^{-1}(\alpha)\right)-\mu_{m}
$$

where $\phi$ is the probability standardised Gaussian distribution function. 


\section{Expected Shortfall (ES) under Gaussian framework}

Equation (19) can be rewritten in a Gaussian framework using VaR definition provided in Equation (17), i.e.

$$
\begin{aligned}
E S_{m}(\alpha) & =\frac{1}{\alpha} \int_{0}^{\alpha}-\mu_{m}-\sigma_{m} \Phi^{-1}(s) \quad d s \\
& =-\mu_{m}-\frac{\sigma_{m}}{\alpha} \int_{0}^{\alpha} \Phi^{-1}(s) \quad d s
\end{aligned}
$$

Consequently, the problem is reduced to the integration of the inverse cumulative Gaussian distribution function from o to $\alpha$. Define a change of variable $s=\Phi(r)$, then $d s=\phi(r) d r$ so $\int_{0}^{\alpha} \Phi^{-1}(s) \quad d s=\int_{-\infty}^{\Phi^{-1}(\alpha)} r \phi(r) d r$ where $\phi$ is the probability Gaussian distribution function. Subsequently,

$$
\begin{aligned}
\int_{-\infty}^{\Phi^{-1}(\alpha)} r \phi(r) d r & =\int_{-\infty}^{\Phi^{-1}(\alpha)} \frac{r}{\sqrt{2 \pi}} \exp \left(-r^{2} / 2\right) d r \\
& =\frac{1}{\sqrt{2 \pi}}\left[-\exp \left(-r^{2} / 2\right)\right]_{-\infty}^{\Phi^{-1}(\alpha)} \\
& =-\phi\left(\Phi^{-1}(\alpha)\right) .
\end{aligned}
$$

As a result the $E S$ is

$$
E S_{m}(\alpha)=-\mu_{m}+\frac{\sigma_{m}}{\alpha} \phi\left(\Phi^{-1}(\alpha)\right)
$$

When the ES has an upper $\left(\alpha^{+}\right)$and a lower bound, the expression is slightly modified

$$
E S_{m}(\alpha)=-\mu_{m}+\frac{\sigma_{m}}{\alpha^{+}-\alpha^{-}}\left\{\phi\left(\Phi^{-1}\left(\alpha^{+}\right)\right)-\phi\left(\Phi^{-1}\left(\alpha^{-}\right)\right)\right\}
$$

\section{A.2 Marginal Expected Shortfall (MES)}

The Marginal Expected Shortfall of financial institution $i$ is the mean loss of firm $i$ when financial market returns are below its $\operatorname{VaR}_{m}(\alpha)$, i.e.

$$
\begin{aligned}
\operatorname{MES}_{i}(\alpha) & =E\left(-r_{i} \mid r_{m}<\operatorname{VaR}(\alpha)\right) \\
& =\int_{0}^{1} P\left(F_{i}\left(r_{i}\right)=s \mid r_{m}<\operatorname{VaR}_{m}(\alpha)\right) F_{i}^{-1}(s) d s
\end{aligned}
$$

where $F_{i}$ is the cumulative distribution function of firm $i$ 's returns and $F_{1}^{-1}$ is its inverse. For the Gaussian case, the MES expression is

$$
M E S_{i \mid m}(\alpha)=\frac{\sigma_{i} \rho_{i m} \phi\left(\Phi^{-1}(\alpha)\right)}{\alpha}-\mu_{i}
$$


Component Expected Shortfall (CES) is directly obtained weighting MES by the market capitalisation for each firm.

\section{Marginal Expected Shortfall (MES) in a Gaussian framework}

$r=\left(r_{m}, r_{i}\right)^{\prime}$ can be expressed as

$$
\left(\begin{array}{c}
r_{m} \\
r_{i}
\end{array}\right)=\underbrace{\left(\begin{array}{l}
\mu_{m} \\
\mu_{i}
\end{array}\right)}_{\mu}+\underbrace{\left(\begin{array}{cc}
\sigma_{m} & 0 \\
0 & \sigma_{i}
\end{array}\right)}_{D^{1 / 2}} \underbrace{\left(\begin{array}{cc}
1 & 0 \\
\rho_{i m} & \sqrt{1-\rho_{i m}^{2}}
\end{array}\right)}_{L}\left(\begin{array}{c}
\Phi^{-1}\left(U_{m}\right) \\
\Phi^{-1}\left(U_{i}\right)
\end{array}\right)
$$

where $L$ matrix represents Choleski decomposition and $\rho_{\text {im }}$ is the correlation parameter. $U_{m}$ and $U_{i}$ are uniform independent distributed variables while $\Phi^{-}$is the inverse cumulative Gaussian distribution function.

The vector $r$ is normally distributed with mean $\mu$ and covariance matrix $D^{1 / 2} L L^{\prime} D^{1 / 2}$. Given a value for financial market returns $r_{m}$, the returns distribution of firm $i$ becomes $r_{i} \mid r_{m} N\left(\mu_{i}+\frac{\sigma_{i} \rho_{i m}}{\sigma_{m}}\left(r_{m}-\mu_{m}\right), \sqrt{1-\rho_{i m}^{2}} \sigma_{i}\right)$, where $N$ refers to the Gaussian distribution where the first input is the mean $\left(\mu_{i m}\right)$ and the second one is the standard deviation $\left(\sigma_{i \mid m}\right)$.

If the realisation of $r_{m}$ is expressed in terms of quantiles, i.e. $r_{m}=\Phi^{-1}(q) \sigma_{m}+\mu_{m}$, the mean value of $r_{i}$ given that $r_{m}$ is in its $q$ quantile is $\mu i+\sigma_{i} \rho_{i m} \Phi^{-1}(q)$, i.e. $E\left(r_{i} \mid r_{m}=\right.$ $\left.\operatorname{VaR}_{m}(q)\right)$. Then, the mean value of $r_{i}$ given that $r_{m}$ is at the most in its $\alpha$ quantile would be

$$
E\left(r_{i} \mid r_{m}<\operatorname{VaR}_{m}(\alpha)\right)=\mu_{i}+\sigma_{i} \rho_{i m} \underbrace{\frac{\int_{0}^{\alpha} \Phi^{-1}(q) d q}{\alpha}}_{E\left(\frac{r_{m}-\mu_{m}}{\sigma_{m}} \mid r_{m}<\operatorname{VaR} R_{m}(\alpha)\right)} .
$$

Because of the solution of previous integral, the MES expression is

$$
M E S_{i \mid m}(\alpha)=\frac{\sigma_{i} \rho_{i m} \phi\left(\Phi^{-1}(\alpha)\right)}{\alpha}-\mu_{i}
$$

\section{A.3 Conditional Expected Shortfall (CoES)}

The Conditional Expected Shortfall of financial institution $i$ given that the financial market $m$ is below its quantile $\alpha$ is expressed as

$$
\begin{aligned}
\operatorname{CoES}_{i \mid m}(\alpha, \beta) & =E_{t-1}\left(-r_{i} \mid r_{i}<\operatorname{CoVaR}(\alpha, \beta)\right) \\
& =\frac{1}{\beta} \int_{0}^{s^{*}} P\left(F_{i}\left(r_{i}\right)=s \mid r_{m}<\operatorname{VaR}_{m}(\alpha)\right) F_{i}^{-1}(s) \quad d s
\end{aligned}
$$


where $s^{*}$ is such that $P\left(F_{i}\left(r_{i}\right)<s^{*} \mid r_{m}<\operatorname{Va} R_{m}(\alpha)\right)=\beta$. In a Gaussian framework this expression can be rewritten as

$\operatorname{CoES}_{i \mid m}(\alpha, \beta)=\sigma_{i}\left(\sqrt{1-\rho_{i m}^{2}} \frac{\phi\left(\Phi^{-1}(\beta)\right)}{\beta}+\rho_{i m} \frac{\phi(\Phi(\alpha))}{\alpha}\right)-\mu_{i}$,

\section{Conditional Expected Shortfall (CoES) in a Gaussian framework}

From Equation (21) and taking under consideration the representation of $r_{t}$ in Equation (22), Equation (9) can be rewritten as

$$
\begin{aligned}
M E S_{i \mid m}(\alpha)= & \sigma_{i}\left\{\frac{\rho_{i m} \phi\left(\Phi^{-1}(\alpha)\right)}{\alpha}-\sqrt{1-\rho_{i m}^{2}}\left(\int_{0}^{\beta} \Phi^{-1}(q) d q+\int_{\beta}^{1} \Phi^{-1}(q) d q\right)\right\}-\mu_{i} \\
= & \underbrace{\sigma_{i} \frac{\rho_{i m} \phi\left(\Phi^{-1}(\alpha)\right)}{\alpha}-\mu_{i}}_{-\mu_{i \mid m}}- \\
& \overbrace{\sigma_{i} \sqrt{1-\rho_{i m}^{2}}}^{\sigma_{i \mid m}} \underbrace{\left(\frac{1}{\beta} \int_{0}^{\beta} \Phi^{-1}(q) d q\right)}_{E(A)} \overbrace{\beta}^{P(A)}- \\
& \overbrace{\sigma_{i} \sqrt{1-\rho_{i m}^{2}}}^{\sigma_{i \mid m}} \underbrace{\left(\frac{1}{1-\beta} \int_{\beta}^{1} \Phi^{-1}(q) d q\right)}_{E\left(A^{C}\right)} \overbrace{(1-\beta)}^{P\left(A^{C}\right)}
\end{aligned}
$$

where

$$
\begin{aligned}
\left.E_{(} A\right) & =E\left(\frac{\left(r_{i}-\mu_{i \mid m}\right)}{\sigma_{i \mid m}} \mid r_{i}<\operatorname{CoVaR} R_{i \mid m}(\alpha, \beta), r_{m}<\operatorname{VaR}_{m}(\alpha)\right), \\
P(A) & =P\left(r_{i}<\operatorname{CoVa} R_{i \mid m} \mid r_{m}<\operatorname{VaR}_{m}(\alpha)\right), \\
E\left(A^{C}\right) & =E\left(\frac{\left(r_{i}-\mu_{i \mid m}\right)}{\sigma_{i \mid m}} \mid r_{i}>\operatorname{CoVaR} R_{i \mid m}(\alpha, \beta), r_{m}<\operatorname{VaR}(\alpha)\right) \text { and } \\
P\left(A^{C}\right) & =P\left(r_{i}>\operatorname{CoVa} R_{i \mid m} \mid r_{m}<\operatorname{VaR}_{m}(\alpha)\right) .
\end{aligned}
$$

From the solution of these integrals,

$$
\begin{aligned}
E(A) & =\frac{-1}{\beta} \phi\left(\Phi^{-1}(\beta)\right) \\
E\left(A^{C}\right) & =\frac{1}{1-\beta} \phi\left(\Phi^{-1}(\beta)\right) .
\end{aligned}
$$

Consequently

$$
\operatorname{CoES}_{i \mid m}(\alpha, \beta)=\sigma_{i}\left(\frac{\sqrt{1-\rho_{i m}^{2}} \phi\left(\Phi^{-1}(\beta)\right)}{\beta}+\frac{\rho_{i m} \phi(\Phi(\alpha))}{\alpha}\right)-\mu_{i},
$$




\section{B Online Appendix}

\section{B.1 Cleaning process of the initial database}

There are two types of cleaning processes in the data downloaded from the confidential financial statements. The first one concerns those funds which, due to its redemption policy or idiosyncratic features, can bias the results of the study. The second one deals with those funds within the scope for which not enough information is gathered from the ISINs of the assets in their portfolios. This lack of information comes from the fact that some funds are investing in other funds and, hence, it is difficult to track the exposure to the credit quality, sector or country of the final assets held. The ownership link between funds creates an interesting transmission channel of contagion. However, the analysis of this link is out of the scope of this article. This study focuses on the systemic risk arising from the liquidity mismatch. From the funds that meet these two cleaning criteria, we focus on the funds that have been active for the period 2009-2020.

In regard to the fund styles which hold a particular redemption policy, the following types of funds are excluded from the analysis:

i) Guaranteed funds have large redemption costs unless the withdrawal is produced at certain dates known as liquidity windows. Taking into account the redemption policy of this type of funds, it is expected to find a pattern of redemptions that differs from the remainder open-end funds. The inclusion of guaranteed funds can generate distortions in the estimation of the parameters of the model.

ii) Passively managed funds with a target return have a redemption policy similar to that of guaranteed funds and have been excluded for the same reasons.

iii) Funds that pay dividends are also excluded because they generate distortions consequence of the effect of the profit sharing on the NAV of the fund. Moreover, these payments also condition the redemption behaviour of investors.

iv) Side pockets and Fund of Hedge Funds (FHF) are deleted from our original sample because their particular features, which are not representative of the Spanish investment fund sector.

v) Funds with a time series shorter than 6 months and an AuM below $€_{1.5}$ million are also removed because low AuM could generate flows, measured as a ratio of the assets of the fund, which are extremely high and the flows pattern could be erratic when funds are recently created.

Concerning portfolio disclosure, only those funds for which at least a $60 \%$ of its AuM can be tracked are considered, i.e. their investment in other funds is lower than $40 \%$ of their AuM. 


\section{B.2 Fund categories}

Funds in the sample are classified into one of the following eight business models:

- $\quad$ Bond funds.

- Sovereign bond funds: Those bond funds which hold more than $40 \%$ of their portfolio in sovereign bonds.

○ Wholesale sovereign bond funds (WB): Those sovereign bond funds whose investors holding more than $€ 150,000$ represent at least a $50 \%$ of the fund AuM.

- Retail sovereign bond funds (RB).

- Corporate bond funds: Those bond funds which hold more than $60 \%$ of their portfolio in corporate bonds.

- Investment grade corporate bond funds (IG).

o High-yield corporate bond funds (HY): Those corporate bond funds which hold more than $20 \%$ of their corporate bond share in bonds with a credit quality below BBB rating.

- Mixed bond funds (MX): Those bond funds that do not meet any of the previous criteria to be categorised as sovereign or corporate bond funds.

- $\quad$ Stock funds.

- Wholesale stock funds (WS): Those stock funds whose investors holding more than $€_{150,000}$ euros represent at least a $50 \%$ of the fund AuM.

- $\quad$ Retail stock funds (RS).

- Other funds (OT): This category includes absolute return funds and global funds. 